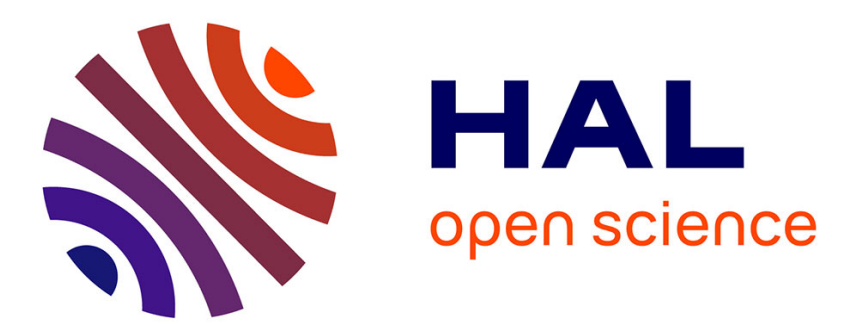

\title{
High rate of adaptive evolution in two widespread European pines
}

Delphine Grivet, Komlan Avia, Aleksia Vaattovaara, Andrew J Eckert, B Neale, Outi Savolainen, Santiago González-Martínez

\section{To cite this version:}

Delphine Grivet, Komlan Avia, Aleksia Vaattovaara, Andrew J Eckert, B Neale, et al.. High rate of adaptive evolution in two widespread European pines. Molecular Ecology, 2017, 26 (24), pp.6857-6870. 10.1111/mec.14402 . hal-01741975

\section{HAL Id: hal-01741975 \\ https://hal.sorbonne-universite.fr/hal-01741975}

Submitted on 23 Mar 2018

HAL is a multi-disciplinary open access archive for the deposit and dissemination of scientific research documents, whether they are published or not. The documents may come from teaching and research institutions in France or abroad, or from public or private research centers.
L'archive ouverte pluridisciplinaire HAL, est destinée au dépôt et à la diffusion de documents scientifiques de niveau recherche, publiés ou non, émanant des établissements d'enseignement et de recherche français ou étrangers, des laboratoires publics ou privés. 
1 High rate of adaptive evolution in two widespread European pines

2

3 Delphine Grivet ${ }^{1,2 *}$, Komlan Avia ${ }^{3,4,5 *}$, Aleksia Vaattovaara ${ }^{3}$, Andrew J. Eckert ${ }^{6}$, David

4 B. Neale ${ }^{7}$, Outi Savolainen ${ }^{3}$, Santiago C. González-Martínez ${ }^{1,2,8}$

5

$6{ }^{1}$ Department of Forest Ecology \& Genetics, Forest Research Centre, INIA-CIFOR, 7 Carretera de la Coruña km 7.5, ES-28040 Madrid, Spain.

8 2Sustainable Forest Management Research Institute, INIA - University of Valladolid, 9 Avda. Madrid 44, 34004 Palencia, Spain.

$10{ }^{3}$ Department of Ecology and Genetics and Biocenter Oulu, University of Oulu, FIN1190014 Oulu, Finland.

$12{ }^{4}$ Algal Genetics Group, UMR 8227, CNRS, Sorbonne Universités, UPMC, Station 13 Biologique Roscoff, CS 9007429688 Roscoff, France.

$14{ }^{5}$ UMI 3614 Evolutionary Biology and Ecology of Algae, CNRS, Sorbonne Universités, 15 UPMC, Pontificia Universidad Católica de Chile, Universidad Austral de Chile, Station 16 Biologique Roscoff, CS 90074, 29688 Roscoff, France.

$17{ }^{6}$ Department of Biology, Virginia Commonwealth University, Richmond, VA 23284, 18 United States.

$19{ }^{7}$ Department of Plant Sciences, University of California at Davis, Davis, CA 95616, 20 United States.

$21{ }^{8}$ BIOGECO, INRA, Univ. Bordeaux, 33610 Cestas, France.

*Equal contributors

Keywords: natural selection, adaptation, Pinus, Distribution of Fitness Effects, adaptive 
evolution

27

28 Corresponding author:

29 Delphine Grivet, Department of Forest Ecology \& Genetics, Forest Research Centre, 30 INIA-CIFOR, Carretera de la Coruña km 7.5, ES-28040 Madrid, Spain.

$31 \quad$ Fax: +34 913476767 Email: dgrivet@inia.es

32

33 Running title (45 char including spaces): Adaptive evolution in two European pines 
34 Abstract $(\leq 250$ words $)$,

36 Comparing related organisms with differing ecological requirements and evolutionary

37 histories can shed light on the mechanisms and drivers underlying genetic adaptation. Here,

38 by examining a common set of hundreds of loci, we compare patterns of nucleotide

39 diversity and molecular adaptation of two European conifers (Scots pine and maritime pine)

40 living in contrasted environments and characterized by distinct population genetic structure

41 (low and clinal in Scots pine, high and ecotypic in maritime pine) and demographic

42 histories. We found higher nucleotide diversity in Scots pine than in maritime pine, whereas

43 rates of new adaptive substitutions $\left(\omega_{a}\right)$, as estimated from the Distribution of Fitness

44 Effects (DFE), were similar across species, and among the highest found in plants. Sample

45 size and population genetic structure did not appear to have resulted in any significant bias

46 in $\omega_{a}$. Moreover, the species-specific population contraction-expansion dynamics did not

47 seem to have affected differentially the rate of adaptive substitution in these two pines.

48 Several methodological and biological factors may underlie the unusually high rate of

49 adaptive evolution of Scots pine and maritime pine. By providing two new case studies with

50 contrasting evolutionary history, we contribute to disentangling the multiple factors

51 potentially affecting adaptive evolution in natural plant populations. 
54 Understanding of the mechanisms of plant adaptation has been advanced through comparative studies of species differing in demographic history (Slotte et al. 2010), effective population size (Gossmann et al. 2012; Strasburg et al. 2011), genetic structure among populations (Wright \& Andolfatto 2008), ecological conditions (Tellier et al. 2011), or phylogenetic relationships (Eckert et al. 2013a; Grivet et al. 2013; Palmé et al. 2009). For long-lived species such as most forest trees, unraveling adaptive processes is challenging, as during their long life-cycle, individuals experience different selective pressures that accumulate over time. Genomic research in forest trees, moreover, has been hindered because of large genome sizes and the lack of model species. Nevertheless, recent advances in tree genomics and reanalysis of common garden experiments have fostered a body of literature that provides insights into the mechanisms underlying forest tree adaptation in space and time. Emerging from these studies are the ideas that forest trees are locally adapted to different environmental conditions, especially to temperature, photoperiod, drought, or biotic stress (see examples in Alberto et al. 2013a; Savolainen et al. 2007), and that they respond to contrasted selection pressure across life stages (Alía et al. 2014). Based on this knowledge, it is of prime interest to identify major environmental drivers of adaptation, as well as the genes involved in the process, as they can help forecast the future distribution of these ecologically important species in the face of climate change. Identifying footprints of natural selection within genomes is complex, as the observed patterns of polymorphism may result from many distinct yet interacting evolutionary forces, including neutral processes such as migration or genetic drift, all acting on variation generated by mutation. Because demography and selection can leave similar 
aiming at attributing these patterns to the action of natural selection must take into account the demographic history of the species, as well as the complex interactions between these two processes (Li et al. 2012; Schrider \& Kern 2016). Tests robust to demography often contrast polymorphism within species with divergence between species. For example, the popular McDonald-Kreitman (MK) test (McDonald \& Kreitman 1991) compares the amount of polymorphism to divergence for categories of sites that are expected to evolve differently (e.g., synonymous/silent vs. non-synonymous). From the original MK test, several extensions have been developed. Two of the most popular are the MKPRF test (Bustamante et al. 2002, 2003, 2005), which is more powerful but is based on specification of a population genetic model, and the more recent SnIPRE test (Eilertson et al. 2012), which is a nonparametric method that does not require estimation of population genetic parameters.

Other methods based on the MK test provide overall estimates of adaptive evolution that can be correlated with population parameters (e.g., effective population size; Gossmann et al. 2012) or environmental characteristics (e.g., Lourenço et al. 2013) in comparative studies. First, the Distribution of Fitness Effects (DFE) of new mutations at functional sites is estimated from polymorphism data and under a specific demographic scenario. Second, the number of substitutions originating from neutral and slightly deleterious mutations is predicted from the estimated DFE (e.g., the method II of Eyre-Walker \& Keightley 2009). Any excess of substitutions (with respect to the neutral expectation) can then be attributed to directional selection, as measured by $\alpha$ (the proportion of adaptive nucleotide substitutions) or $\omega_{a}$ (the relative rate of adaptive substitutions scaled by the rate of neutral substitution) (Bierne \& Eyre-Walker 2004; Eyre-Walker \& Keightley 2009; Smith \& EyreWalker 2002). Although $\alpha$ has been extensively used (e.g., (Eckert et al. 2013a; Gossmann et al. 2010; Slotte et al. 2010; Strasburg et al. 2011), this estimate is of limited value for 
estimating the efficiency of the adaptive process, because $\alpha$ is also influenced by the rate of non-adaptive substitutions (Gossmann et al. 2012). The parameter $\omega_{a}$, which is roughly equivalent to $K_{a}$ (the number of non-synonymous substitutions per non-synonymous site), is thus more appropriate for comparing adaptive evolution across genomic regions or species (Gossmann et al. 2012; Lourenço et al. 2013).

In the present study, we assess the effect of distinct demographic histories and selection regimes on inferences of adaptive evolution for two widespread conifer species. Scots pine (Pinus sylvestris L.) is widely and continuously distributed in Eurasia, occupying regions that differ greatly in climate (Krakau et al. 2013). Its demographic history is characterized by an ancient bottleneck (Kujala \& Savolainen 2012; Pyhäjärvi et al. 2007) and limited population genetic structure, which is only found along the margins of its wide range (Gullberg 1985; Kujala \& Savolainen 2012; Pyhäjärvi et al. 2007). The absence of genetic structure shown by molecular markers across much of its range, however, is not indicative of a lack of quantitative trait variation across populations (Andersson \& Fedorkov 2004; García-Gil et al. 2003; Notivol et al. 2007; Oleksyn et al. 1998). In particular, strong clines in photoperiod-related traits are often observed across latitudinal gradients in the species (e.g., for timing of growth cessation and budset; see Beck et al. 2004; Hurme et al. 1997; Mikola 1982; Oleksyn et al. 1998).

In contrast to Scots pine, maritime pine (Pinus pinaster Ait.) is patchily distributed across the western Mediterranean Basin and the Atlantic regions of Portugal, Spain and France. This conifer grows in warm temperate regions with an oceanic influence on climate (Abad Viñas et al. 2016), and is particularly well adapted to dry and fire-prone environments. Its demographic history is characterized by a more recent bottleneck relative to Scots pine (Naydenov et al. 2014), and it has a strong genetic structure among populations across its range (e.g., Burban and Petit 2003; Bucci et al. 2007; Jaramillo- 
127 Correa et al. 2015) that is accompanied by morphological and physiological differences

128 (Kremer and Roussel 1986; Alía et al. 1995; Santos del Blanco et al. 2010; Lamy et al. 2011; Corcuera et al. 2012), defining various subspecies and eco-types (Richardson 1998). This genetic structure likely results from post-Pleistocene events (Burban and Petit 2003; Bucci et al. 2007; Naydenov et al. 2014), including adaptation to local climate (Serra132 Varela et al. 2015).

Given the large differences between Scots pine and maritime pine with respect to their climatic niches, we focused on genes for general responses to different type of abiotic stress. This is also consistent with previous studies ranking the importance of different fitness-related traits for local adaptation in the species (for Scots pine see Castro et al. 2002; Galiano et al. 2010; Ryyppö et al. 1998; and for maritime pine see Corcuera et al. 2011; Gaspar et al. 2013; Lamy et al. 2014; Ramírez-Valiente \& Robledo-Arnuncio 2014). Then, we used complementary methods to get insights into the action of selective forces, both at specific genes and genome-wide, and considered the specific demographic, ecological and historical settings of each species to discuss the possible factors (both methodological and biological) that may explain our results. Our hypotheses are: i) Scots pine has high nucleotide diversity resulting from its large distribution and expected large effective population size; ii) Large effective population size in Scots pine would have also resulted in higher efficiency of selection and thus a higher number of fixed adaptive substitutions (see also Gossmann et al. 2012); and iii) the highly fragmented distribution in maritime pine would have resulted in lower levels of overall adaptive evolution. Scots pine and maritime pine, with their contrasting characteristics, allow for exploring how different biological factors may interact with natural selection and adaptive evolution in plants. 
Scots pine was sampled across 8-10 populations from its western range (Figure 1 and Table

S1) for eight loci from six candidate genes for abiotic stress response and phenology (3-20 individuals per population, and a total of 36-115 individuals per locus), and across a smaller number of populations (7) for the much larger CRSP (Comparative Re-Sequencing in Pinaceae initiative; http://dendrome.ucdavis.edu/NealeLab/crsp/; see Wegrzyn et al. 2008) set of 364 loci (1-2 individuals per population, and a total of 6-12 individuals per locus). In a first phase, maritime pine was sampled across 10-12 populations from its full range (Figure 1 and Table S1) for the same eight abiotic stress response and phenology loci as for Scots pine (1-19 individuals per population for a total of 49-100 individuals per locus), and across 11 populations for the CRSP gene dataset (1-3 individuals per population for a total of 6-14 individuals per locus). More details on the gene datasets are presented in the Sequence data section. In a second phase, another dataset produced in maritime pine comprising 128 loci common with the CRSP dataset (2-4 individuals per population for a total of 28-36 individuals per locus) was obtained within the Conifer Re-sequencing Initiative for European Conifers (CRIEC, www.evoltree.eu; Figure 1 and Table S1). This dataset with more individuals per population was examined in order to study the effect of sample size and population structure on the DFE-based estimates. Finally, the CRSP and the

172 CRIEC datasets were combined for the 128 loci in common (2-6 individuals per population 173 for a total of 34-49 individuals per locus) to reach a bigger sample size for the statistical analyses (“extended CRSP” dataset). Sequence datasets used for the different analyses are detailed in Figure S1. 

sampling related trees (i.e., leaving a minimum distance of $50 \mathrm{~m}$ between sampled individuals) and without any phenotypic selection.

Sequence data

181 Sequence alignment and editing

Eight loci from previously studied candidate genes, including two full-length genes (coL1 and gia), were amplified with available primers from different sources (see Table S2). Another 1,600 gene amplicons (hereafter referred as the CRSP gene set) were obtained by resequencing in seven conifers (including Scots pine and maritime pine) some loci originally developed in loblolly pine, Pinus taeda (Eckert et al. 2013b). For both gene sets, DNA sequences were obtained by direct sequencing from haploid seed megagametophytes. In this way, (i) phase is directly known and does not need to be estimated and (ii) coamplification of paralogs, a common problem in plant species with large genomes such as conifers, is more easily detected. For the CRSP gene set, loci with at least six successfully sequenced individuals in both Scots pine and maritime pine were accepted for further analyses. This led to 491 loci that were subsequently checked manually and edited with Codon Code Aligner (CodonCode Corporation, Centerville, MA, USA) or Sequencher 4.7 (Gene Codes Corporation, Ann Arbor, MI, USA). Low quality sequences were removed, as well as putative paralogous genes based on phylogenies including the three pines (the two target species together with loblolly pine), as detected by PRANK runs with default parameters (Löytynoja \& Goldman 2005). This last quality-filtering step led to a set of 389 loci common to the two target species. 
201 Gene annotation for all loci was obtained from homology with loblolly pine EST contigs 202 and the NCBI reference protein database using Geneious version 6.1 (Biomatters, 203 Auckland, New Zealand). All 389 genes had high sequence similarity with loblolly pine 204 genes, suggesting low copy-number genes and orthology across the different species. The 205 biological function of the genes was determined based on their homology with the 206 Arabidopsis thaliana and/or Pinus taeda protein database with an E-value threshold of $10^{-10}$ 207 (see Table S3) and the Protein Knowledgebase - UniProtKB 208 (http://www.uniprot.org/uniprot/). Of the 389 genes, 364 could be annotated, leading to a total of 372 annotated loci in the two species when adding the eight previously-studied candidate gene loci. Loblolly pine was used as outgroup when needed.

\section{$\underline{\text { Target and reference genes }}$}

213 The 372 loci under study, as well as their annotations, are publicly available (NCBI GenBank: MF385275-MF385581 and MF385585-MF397901). From these 372 loci, 64 were selected as target genes, including the eight previously-studied candidate gene loci

216 (see Table S2 for details and references) and 56 other annotated loci selected from the 217 CRSP dataset (see above). All 64 target genes had highly confident annotation associated to adaptive traits: 48 loci related to abiotic stress responses (mostly cold, heat, drought, salt and other oxidative stresses); and 16 loci related to photosynthesis and photosystem (9 loci), and phenology (7 loci). Only target genes were tested for footprints of selection.

The reference genes consisted of all other loci (308) from the CRSP dataset, 222 including loci with unknown function or loci for which there is no evidence of involvement in forest tree adaptation. Because of implementation limitations and statistical power requirements (i.e., the minimum number of required segregating sites) in the MKPRF test (see below), reference genes were combined for this analysis into compound loci. All loci 
with a known position on a genetic map (loblolly pine, Eckert et al. 2010; maritime pine,

227 Chancerel et al. 2011; and our own unpublished genetic map of Scots pine) were grouped according to the linkage groups forming 28 compound loci (see Table S4). To balance the number of loci used in the MKPRF test (64 target versus 28 compound reference loci), we used also 36 other reference loci selected at random among those reference genes not included in the compound loci to also reach 64 loci for the reference group in which the statistical power was mainly driven by the compound loci (higher number of segregating sites).

Nucleotide diversity, genetic divergence and overall patterns of polymorphism

Nucleotide diversity $\pi$ (Nei \& Li 1979) and Watterson's $\theta_{w}$ (Watterson 1975) were calculated for all sites, as well as separately for silent, synonymous and non-synonymous sites, in Scots pine and maritime pine. For each species, the divergence from loblolly pine was characterized by the number of synonymous substitutions per synonymous site $\left(K_{s}\right)$ and of non-synonymous substitutions per non-synonymous site $\left(K_{a}\right)$, both with Jukes-Cantor correction, and their ratio $\left(K_{a} / K_{s}\right)$, as well as the statistics of shared and fixed segregating sites requested by some of the neutrality tests (see below).

To identify overall differences in patterns of polymorphism across species, different statistics were computed based on the observed Site Frequency Spectrum (SFS): Tajima’s D (Tajima 1989), which evaluates the difference between low- and intermediate-frequency variants; Zeng et al.’s E (Zeng et al. 2006), which evaluates the difference between lowand high-frequency variants; and the normalized Fay and Wu's $H$ ( $H_{n}$; Zeng et al. 2006), which evaluates the difference between intermediate- and high-frequency variants. These statistics were computed, separately, for the 64 target loci and the 308 reference loci, and compared with those under a standard neutral equilibrium model (constant population size). 
All nucleotide diversity statistics were computed using MANVa and mstatspop

252

253

254

255

256

257

258

259

260

261

262

263

264

265

266

267

268

269

270

271

272

273

274

275

(https://bioinformatics.cragenomica.es/numgenomics/people/sebas/software/software.html), and, when needed, the SDMTools package in $\mathrm{R}$ was used to correct for sample size variation across loci, by weighting means and standard deviations.

\section{Neutrality tests robust to demography}

To identify potential genes under selection, we first used the SnIPRE approach (Eilertson et al. 2012), which considers polymorphism and divergence data from synonymous/silent and non-synonymous sites under a Poisson Random Effect model. This method is based on the McDonald-Kreitman test, and it can reliably identify genes under weak and strong negative as well as positive selection, without requiring the specification of a population genetic model. We considered both the selection (specific selection effect of a gene relative to neutrality) and constraint (proportion of non-synonymous mutations that are non-lethal, thus having effects on counts) effects provided by the program. The selection effect is useful to identify selection on mildly deleterious and advantageous mutations, while the constraint effect is useful to identify strong negative or purifying selection (Eilertson et al. 2012). Thus, significant effects on sequence data are classified as being neutral, negative or positive.

Second, we used the McDonald-Kreitman Poisson Random Fields (MKPRF) test (Bustamante et al. 2002, 2005), which implements a Markov chain Monte Carlo (MCMC) Bayesian approach to estimate parameters of the Poisson Random Field (PRF) model (Sawyer \& Hartl 1992), allowing to compare groups of genes for selection signatures. MKPRF not only identifies non-neutrally evolving loci but it also estimates the associated strength of selection $\left(\gamma=2 N_{e} s\right)$. The MKPRF analysis was run using the mkprf program (kindly provided by Carlos D. Bustamante and Adam Boyko), with the following 
parameters: 10 independent MCMC chains per run and 10,000 samples from each chain drawn on every 10 steps, after burn-in of 1,000 steps. Default values were used for prior distributions and other MCMC parameters. Convergence of the MCMC runs was checked in the MCMC output files generated by the program.

\section{Distribution of fitness effects (DFE) and adaptive evolution}

We used a method based on the DFE to estimate the overall rates of adaptive substitutions $\left(\omega_{a}\right)$ : the method II of Eyre-Walker and Keightley (2009) as implemented in the DoFE 3.1 program. This method accounts for demographic changes that can affect the shape of the SFS by comparing the observed folded SFS at neutral sites to the folded SFS expected from neutral mutations in a stationary population at equilibrium and assumes that demography has the same proportional effect on the SFS of selected sites.

Input files were created using Python and Perl scripts kindly provided by Jaakko Tyrmi and Adrian Schneider, respectively (available upon request). To build the input files for the method II of Eyre-Walker and Keightley (2009), we computed the statistics for nonsynonymous sites and synonymous sites, at the intraspecific level (for Scots pine and maritime pine, respectively) and at the interspecific level (using loblolly pine as outgroup for each target pine) using the same number of alleles per species and dataset: 305 loci with 10 alleles each for Scots pine and 291 loci with 11 alleles for maritime pine for the CRSP datasets; 126 loci with 23 alleles each for the CRIEC dataset. The other input statistics were then computed with MANVa (see above) using the same reduced datasets.

Loblolly pine was used as outgroup for both Scots pine and maritime pine and, thus, DFE-based estimates of adaptive evolution for these two pine species were done along a partially shared branch. In phylogenetically close species, shared divergence with the outgroup may result in differences in $\omega_{a}$ mainly due to differences in within-species 
301

polymorphism, i.e., estimates can be biased if the nucleotide divergence between the species is low relative to within species variation (Keightley \& Eyre-Walker 2012). To exclude this potential source of bias, shared divergence between loblolly pine and Scots pine/maritime pine was estimated using two approaches. First, one, three or five sequences from each locus and species were randomly sampled and concatenated, leading to three aligned fasta files. Aligned fasta files were subsequently used to build unrooted phylogenetic trees using PhyML (Guindon \& Gascuel 2003). The analyses were run with default parameters, using the General Time Reversible (GTR) model (Tavaré 1986), and for all sites, and both 0 -fold and 4-fold degenerate sites. The proportion of shared divergence was estimated then as the fraction of the sum of branch lengths due to the common branch leading to loblolly pine (i.e., the common branch leading to loblolly pine divided by the total sum of branch lengths). Second, fixed differences between loblolly pine and both Scots pine and maritime pine were counted, and shared fixed differences were directly obtained for all sites as well as for 0-fold and 4-fold degenerate sites.

\section{Results}

Nucleotide diversity, genetic divergence and overall patterns of polymorphism

The two pines showed a significant difference (non-overlapping 95\% confidence intervals) in nucleotide diversity, with Scots pine $\left(\theta_{w-s y n}=0.00687,95 \%\right.$ CI: $\left.0.00594-0.00781\right)$ displaying 1.64 times the nucleotide diversity of maritime pine $\left(\theta_{w \text {-syn }}=0.00419,95 \% \mathrm{CI}\right.$ : 0.00362-0.00476) (Table 1). In both species, the overall $K_{a}, K_{s}$, and $K_{a} / K_{s}$ ratios (relative to loblolly pine) were similar, with overlapping 95\% confidence intervals (data not shown), indicating equal divergence from loblolly pine $\left(K_{s}\right.$ of 0.0323 for Scots pine and of 0.0375 
326 for maritime pine) and similar rates of evolutionary constraint (Table 1). Scots pine and 327 maritime pine only shared about $2-4 \%$ of their synonymous polymorphic sites (depending on the species used as outgroup). revealed different polymorphism patterns in the two pines (Table 2). Scots pine displayed an excess of low-frequency variants compared to intermediate-frequency (Tajima's $D$ ) and high-frequency (Zeng et al.’s E) variants, but no differences between intermediate- and high-frequency (Fay and Wu's $H_{n}$ ) variants. In contrast, maritime pine displayed no difference of intermediate- with respect to low-frequency variants (Tajima's $D$ ), and an excess of high-frequency variants compared to low-frequency (Zeng et al.'s E) and intermediate-frequency (Fay and Wu's $H_{n}$ ) variants. Thus, overall, Scots pine displayed an excess of low-frequency variants, while maritime pine showed an excess of high-frequency variants. This pattern is present in both target and reference loci suggesting that demographic processes (and not selective processes) underlie the observed differences between the two pines. The impact of population structure on the statistics is reflected especially by Fay and Wu's $H_{n}$, which is more sensitive to population subdivision (Zeng et al. 2006), and that deviates more strongly from the standard neutral model in the species with stronger population structure (i.e., maritime pine).

Neutrality tests robust to demography

The robust-to-demography SnIPRE method (Empirical Bayes and Bayesian SnIPRE tests) suggested four and three target genes as being under selection in Scots pine (3 positive and 1 negative selection events) and maritime pine (2 positive and 1 negative selection events), respectively (Table 3 and Table S5). Overall, the 64 target loci had a positive average selection effect in Scots pine, while in maritime pine such effect was not observed (Figure 
S2). All genes found under selection with the MKPRF test but one for Scots pine (five and two for Scots pine and maritime pine, respectively) were among those revealed by the SnIPRE method (Table 3). As expected, a higher proportion of loci from the previouslystudied candidate gene dataset (see Material and Methods) was found under selection (50\% and $25 \%$ based on the two methods in Scots pine and maritime pine, respectively) compared to the CRSP dataset ( $0.27 \%$ and $0.55 \%$, respectively). Two of these genes were common to both pines using the two methods, with the same pattern of negative (dhn1) and positive (coL1) selection.

\section{Distribution of fitness effects (DFE) and adaptive evolution}

The inferred DFE using DoFE was similar for the two pines, with most of the mutations being strongly deleterious and subject to purifying selection (Figure 2). However, there were also some differences in the DFE spectrum. Scots pine had a significantly higher proportion of deleterious mutations for the three classes with the least deleterious mutations, while the opposite pattern was observed at the other extreme of the DFE spectrum with about $77 \%$ of mutation being highly deleterious for Scots pine and about $85 \%$ for maritime pine. Increasing the sample size for maritime pine (the "extended CRSP" dataset, see Sampling section) resulted in higher proportion of the three classes with the least deleterious mutations but still in lower proportion compared to Scots pine, while the pattern was the opposite for highly deleterious mutations (Figure 2). In terms of adaptive substitutions, both species displayed a relative rate significantly different from zero (Scots pine $\omega_{a}=0.1156$ vs. maritime pine $\omega_{a}=0.1535$ ), with no significant differences between them (overlapping 95\% CIs, see Figure 2). Increasing the sampling size for maritime pine (“extended CRSP” dataset) led to a slightly smaller $\omega_{a}(0.1447)$, not different from that estimated with the CRSP datasets for Scots pine and maritime pine (Figure 2). Estimating $\omega_{a}$ with a simple 
376 and non-parametric method $\omega_{a}=\frac{d_{N}-d_{S}\left({ }^{P_{N}} / P_{S}\right)}{d_{S}}$ (Gossmann et al. 2010; Kousathanas et al. 2014) gave $\omega_{a}=-0.0740$ with $95 \%$ CIs $(-0.2430 ; 0.0871)$ for Scots pine and $\omega_{a}=0.0976$ with 95\% CIs $(-0.0778 ; 0.2867)$ for maritime pine. These estimates confirmed the trend of a higher $\omega_{a}$ in maritime pine than in Scots pine, albeit differences were still not significant (i.e., overlapping CIs).

Shared divergence between loblolly pine and Scots pine/maritime pine was estimated using two approaches. First, a three-species unrooted phylogenetic tree was built using 168,534 bp of concatenated sequences, which showed only $43 \%$ of shared divergence due to the common branch from loblolly pine to Scots pine/maritime pine (Figure S3). A similar estimate was obtained for 0 -fold and 4 -fold degenerate sites (43 to $44 \%$ of shared divergence). Furthermore, we obtained the same estimates with one, three or five sequences randomly-sampled from each locus and species. Second, counts of fixed differences between loblolly pine and Scots pine/maritime pine showed 629 (all sites), 152 (0-fold degenerate sites) and 106 (4-fold degenerate sites) mutations specific to the Scots pine lineage, while these numbers were 960, 196 and 185 mutations, respectively, for maritime pine (Table S6).

\section{Discussion}

The comparison of the same sets of loci between Scots pine and maritime pine, two related species that occupy different ecological niches and are characterized by different evolutionary histories, allows for exploring how different biological factors may interact with natural selection and adaptive evolution in plants. We discuss how our results are in agreement with each species evolutionary history, as well as how the comparison between 
401 species helps to better understand the evolutionary forces responsible for the observed molecular pattern.

403

404

Nucleotide diversity

405

This study presents the first large set of loci sequenced in a range-wide sample of two important European conifers. The primers used in this study were transferred from a related New World species, loblolly pine, and thus may suffer from ascertainment bias due to enrichment with low-diversity conserved genes. To test this hypothesis, we compared a set of 364 loblolly pine loci orthologous to those used in this study with 1,000 sets of 364 loci randomly selected with replacement from a larger set of ca. 6,000 loci available in this species (see Eckert et al. 2013b). This comparison indicated a significant bias towards lower nucleotide diversity in our gene set (i.e., non-overlapping 95\% confidence intervals), but only when considering statistics for all sites (see Table S7). This suggests that comparisons based on synonymous/silent sites or even non-synonymous sites in our study are subject to only limited bias. Moreover, because the ascertainment bias would affect both species in the same way, it would not prevent a comparative analysis between the two pines, which is the main focus of this study.

The sequencing of the same 372 loci in both pines revealed significantly higher nucleotide diversity in the widespread and continuously distributed Scots pine than in the narrower and more patchily distributed maritime pine. Only a limited number of genes has

421 been sequenced for each pine (and rarely the same genes across species) in previous studies, 422 making interspecific comparisons difficult. Watterson's nucleotide diversity for silent sites 423 (compare with Table S8) in Scots pine was 0.00525 for 16 loci (Pyhäjärvi et al. 2007), and 0.00620 for 11 loci (Kujala \& Savolainen 2012); while that of maritime pine was 0.00824 for 11 loci (Eveno et al. 2008), but was only 0.00280 for six other loci (Grivet et al. 2011) 
426 To test whether using a smaller gene set could lead to biased nucleotide diversity estimates,

427 we subsampled different number of loci from the total 372 in our study, and compared 428 nucleotide diversity for these subsamples. Subsampling for 10, 50 or 100 loci did not affect average nucleotide diversity estimates (see confidence intervals in Table S9), suggesting that the number of genes used did not necessarily lead to bias. Nevertheless, subsets of specific genes may indeed have substantially different levels of nucleotide diversity. For example, the set of six previously-studied candidates genes (see Material and methods) showed higher nucleotide diversity (Scots pine $\theta_{w \text {-silent }}=0.00895$; maritime pine $\theta_{w-}$ silent $=0.00664$ ) than the 372-locus average (Table S8). These results show that nucleotide diversity can only be properly compared across species when using a large set of (preferably) common genes, as this estimate can be very variable across small specific gene sets.

Insights into demographic history

Patterns within the SFS for each species (as summarized by statistics such as Tajima's $D$, Zeng et al.’s $E$, and Fay and Wu's $H_{n}$ ) can provide insights into demographic history (see references in Gravel et al. 2011). In Scots pine and maritime pine, they reflected relatively well what is known for each pine species. Scots pine has likely been through a very ancient ( 1-2 Ma) and severe (shrinking populations to about 1\% of present time population size) bottleneck (Pyhäjärvi et al. 2007). In more recent times, the species would have recolonized a vast territory in northern, central and Eastern Europe, reaching northern Fennoscandia 447 some 10,000 to 7,000 years ago (see Pyhäjärvi et al. 2007, 2008; Savolainen et al. 2011; 448 Kujala et al. 2012; Cheddadi et al. 2006; Naydenov et al. 2007). This wide-range colonization process would have led to a weak population genetic structure in Scots pine (except especially at the southern margins) (Cheddadi et al. 2006; Dvornyk et al. 2002; 
451 García-Gil et al. 2003; Karhu et al. 1996; Pyhäjärvi et al. 2007). The excess of low452 frequency variants in this species could have originated during repeated long-range 453 expansions and would correspond (mostly) to relatively new mutations (but likely before 454 the most recent ice age). In contrast, maritime pine has likely survived in multiple glacial 455 refugia (Bucci et al. 2007; Burban \& Petit 2003), from which it would have recolonized its 456 current range around the Last Glacial Maximum ( 20,000 years ago; Naydenov et al. 2014). 457 Its spatially limited expansion, combined with population fragmentation, would have led to 458 distinct and regionally restricted gene pools (Bucci et al. 2007; Burban \& Petit 2003; Jaramillo-Correa et al. 2015), which would have been relatively stable across time, leading to the accumulation of high-frequency variants when considering full-range SFS patterns. Because of the very distinct demographic histories of the two pines, we used methods integrating demography to characterize their pattern of adaptive evolution at the molecular level and to test loci for signatures of positive and negative selection.

\section{Genes under selection}

Three dehydrins were found to be under selection in the two pines. Previous studies looking at various members of this family, and using different approaches (neutrality tests, $F_{S T^{-}}$ outlier detection, allele frequency-environment correlations), also showed the action of natural selection on dehydrin genes: dhn1, dhn3 and dhn9 in Scots pine (Palmé et al. 2009; Wachowiak et al. 2009); dhn1 (Eveno et al. 2008), dhn2 and dhn5 (Grivet et al. 2011) in maritime pine. In this study, two new dehydrin genes (dhn2 and dhn5) were identified as

472 possible targets of positive selection in Scots pine, while our results confirmed the adaptive role of $d h n 1$ in maritime pine. Gene expression of dehydrins in water stress experiments pointed to their involvement in drought resistance in maritime pine (Perdiguero et al. 2012; Velasco-Conde et al. 2012). They have also been shown to be involved in wounding, cold, 
and drought stress response in white spruce and loblolly pine (Lorenz et al. 2011; Richard et al. 2000; Watkinson et al. 2003). Altogether these studies point to the pivotal role of dehydrins in conifer adaptive response to abiotic stress, over the short- $\left(F_{S T}\right)$ and long-term (SnIPRE) timescale, emphasizing their importance.

An interesting case is that of locus $0 \_4042 \_01$ which showed a signal of positive selection in maritime pine (16 fixed non-synonymous mutations compared to only three in Scots pine). Locus $0 \_4042 \_01$ shows high similarity (E-value of $2 \times 10^{-21}$ ) with glutathione S-transferase (gst) in Arabidopsis thaliana, an enzyme involved in secondary metabolism response to the processes of detoxification and stress response to cold (Goulas et al. 2006), salt (Jiang et al. 2007), and pathogens (Jones et al. 2006). In the Chinese pine, Pinus tabuliformis, five residues within gst were found under positive selection, four of them involved in the enzyme activity and specificity (Lan et al. 2013). Interestingly, one of these residues codes for a different amino acid in maritime pine (a proline) compared to loblolly pine (alanine), while in Scots pine most individuals maintain the putative ancestral form. This amino acid (positions 31-33) is located very close to the catalytically active G-site in the spatial conformation of the protein, and the substitution of this residue could cause structural changes in the GSH binding pocket (where the conjugation of intracellular glutathione to a wide variety of molecules occurs; Lan et al. 2013).

Finally, constans-like 1 (coL1), which was found under positive selection in both pines, codes for a putative transcription factor suggested to affect flower development in Arabidopsis (Ledger et al. 2001). In trees, homologues to constans are involved in bud development (Alberto et al. 2013b; Ruttink et al. 2007), as well as in photoperiodic control of shoot elongation (Holefors et al. 2009). Evidence of selection on constans-like genes, moreover, has been found in poplar (Chen et al. 2014; Ma et al. 2010; Ruttink et al. 2007; 
500 Smith et al. 2004; Wei et al. 2013), spruce (Holliday et al. 2010), oak (Lind-Riehl et al. 501 2014), and the perennial Arabidopsis lyrata (Mattila et al. 2016).

502

503

Distribution of fitness effects (DFE) and adaptive evolution

504 Scots pine and maritime pine case studies provided new insights on conifer adaptive 505 evolution and the evolutionary forces shaping conifer genomes. The DFE was similar 506 between the two pines and to other plants (e.g., Eckert et al. 2013a; Gossmann et al. 2010), 507 as well as to various other organisms (see references in Eyre-Walker \& Keightley 2007), 508 with most of the mutations being strongly deleterious and subject to purifying selection. 509 Compared to other conifers (and plants) however (see Eckert et al. 2013a, and Hodgins et 510 al. 2016), both targeted pines presented an atypical pattern with a lower proportion of slightly deleterious mutations and a higher proportion of highly deleterious mutations. The relative rates of new adaptive substitutions $\left(\omega_{a}\right)$ for Scots pine $(0.1156)$ and maritime pine (0.1535) were within the range found in other species (between -0.14 and 0.31; Gossmann et al. 2012), although at the upper range limit for plants (Gossmann et al. 2010, 2012) as well as higher by a factor over two than those estimated with the same methodology in other pines $\left(\omega_{a}=\right.$ from -0.0477 to 0.0325 for 11 species of soft pines in Eckert et al. 2013a; $\omega_{a}=0.0592$ for lodgepole pine in Hodgins et al. 2016).

Several outcomes emerge from these results. First, sampling intensity may bias the estimate of DFE and $\omega_{a}$, as illustrated by the "extended CRSP dataset" that led to weaker differences between the two pines. Second, albeit very distinct in terms of their evolutionary

521 histories (i.e., demographic history, population structure, and effective population size), the two pines present similar rates of adaptive evolution. This suggests that other factors may also govern the efficacy of selection across these taxa (see below). Third, it is noteworthy to

524 highlight the high efficiency of natural selection at purging highly deleterious mutations as 
well as the high rate of positive selection in both pines, in regards to plants in general and more specifically to other conifers studied so far. Plants tend to have low rates of adaptive evolution, linked to contracting populations and a high level of population structure (Gossmann et al. 2010). Since pines present in general large effective population size, being also relatively undomesticated species, it is expected that they display also high rates of adaptive evolution. However, this trend was not found in previous studies including pines, suggesting that other factors, still largely unknown, may also be relevant (Chen et al. 2017). The reliability of our estimates may depend on methodological factors, among them the choice of the loci under study, the outgroup species, or the analytical method, as well as the sampling intensity and distribution (Eckert et al. 2013a; Phifer-Rixey et al. 2012; Städler et al. 2009). More specifically, (i) because we used mostly primers transferred from another species (loblolly pine), gene sets in our study may be more conserved and thus undergo less adaptive evolution (Bachtrog 2008; Eckert et al. 2013a; Gossmann et al. 2010); notice that this would make even more remarkable the high $\omega_{a}$ found in both pines. (ii) Different genic regions may be under different evolutionary constraints (e.g., Hodgins et al. 2016), and therefore lead to different estimates of adaptive evolution. We computed DFE and $\omega_{a}$ for silent sites (intron + untranslated regions, UTR) and found lower rates of positive selection (data not shown) although not significantly different from those estimated with synonymous sites. (iii) Recombination and mutation rates may differ among selected loci and thus can directly affect the proportion of segregating sites (Bachtrog 2008). (iv) The level of divergence of the species of interest with the outgroup may reveal different proportion of segregating sites, i.e., the closer the outgroup the fewer differences will be detected (Gossmann et al. 2010; Strasburg et al. 2011). In our study, low phylogenetic distance and partial sharing by the targeted species of the branch conducting to the outgroup could have overestimated $\omega_{a}$ (Keightley \& Eyre-Walker 2012). However, phylogenetic 
analyses indicated less than $50 \%$ of shared divergence between loblolly pine and each of the targeted species suggesting that observed patterns were not only due to within-species polymorphism. Furthermore, counts of fixed differences between the outgroup and each of the targeted species pointed to sufficient level of lineage specific mutations in both Scots pine and maritime pine as to correctly estimate $\omega_{a} .(\mathrm{v})$ The choice of the methodology used to infer adaptive evolution (Eckert et al. 2013a; Welch 2006) may give different output. By selecting the same loci and outgroup, as well as the same methodology for the two pines and the main studies in other organisms, we attempted to control for these factors and ensured that the estimates (although probably conservative, see point (i)) were comparable across species. Finally, both sampling intensity and distribution may have affected our estimate of adaptive evolution rate. (vi) To test effects of sampling intensity, in terms of both individuals and loci, first, the CRSP dataset (less samples per population but more loci) was compared with the "extended CRSP” dataset (more samples per population but fewer loci) in maritime pine and, second, simulated datasets with different number of loci were compared. Neither approach suggested any effect of sampling intensity on our estimates. (vii) Sampling scheme influences what aspects of the history are emphasized (see Städler et al. 2009). Scots pine populations were sampled from both the main range (Finland, Sweden and Poland) and the margins (Spain, Italy and UK), representing fairly well the species evolutionary history overall. Nevertheless, there may still be a bias in Scots pine estimates, as the CRSP loci were not sampled across the full species range (in particular the eastern-northern range was poorly sampled). Thus, some apparently fixed non-synonymous mutations may show polymorphism in the unsampled range, resulting in an upward bias. In maritime pine, however, this bias should be minimal (if any) as populations were sampled across its full range, considering all gene pools known in the species. In addition, population genetic structure does not seem to have affected the 
575 proportion of adaptive substitutions, with estimates being similar between the weakly

576 structured Scots pine and the highly structured maritime pine, and still higher than

577 published estimates for other species. Finally, other factors may constrain selective forces,

578 as suggested by comparative studies and theoretical work, and may have influenced the

579 estimates of adaptive evolution in the two pines (Galtier 2016; Lanfear et al. 2014): genetic

580 draft and background selection (Messer \& Petrov 2013; Peischl et al. 2013), environmental

581 heterogeneity (Tellier et al. 2011), phenotypic space dimensionality (i.e., fitness landscape)

582 and rate of environmental change (Gillespie 2001; Lourenço et al. 2013). These factors are

583 challenging to tease apart.

584

585 Conclusion

586 By analyzing a common set of 372 gene loci, we detected specific patterns of molecular 587 evolution and adaptation in two widespread European conifers. First, as expected, 588 nucleotide diversity was higher in the continuously distributed Scots pine than in the 589 patchily distributed maritime pine. Second, by using methods that incorporate demographic 590 effects, we detected an unexpected high relative rate of adaptive substitutions in both pines, 591 and in particular in maritime pine. Although we cannot fully discard methodological 592 caveats, these high rates of adaptive evolution do not seem to be correlated with population 593 genetic structure nor demographic histories that differ between the two pines. Altogether, 594 our results suggest that more than one factor may be responsible of the high rate of adaptive 595 evolution found in these two emblematic pine species, with several factors being difficult to 596 tease apart. 
601 We are grateful to Carmen García-Barriga (laboratory), Mario Zabal-Aguirre (sequence 602 editing), Kirsten Eilertson (SnIPRE), Jaakko Tyrmi (Python script), Adrian Schneider 603 (method for inferring the DFE), Sebastián E. Ramos-Onsins (MANVa) and Athanasios 604 Kousathanas (DFE) for valuable information exchanges, as well as to Adam Eyre-Walker 605 and various anonymous reviewers for constructive comments. This work was supported by 606 the EU EVOLTREE Network of Excellence, AdapCon project (CGL2011-30182-C02-01) 607 from the Spanish Ministry of Economy and Competiveness, TipTree project (BiodivERsA608 ERANET) and EcoGenPin project (IdEx Bordeaux - Chaires d'installation 2015). D.G. 609 acknowledges support from the Spanish Ministry of Economy and Competiveness through a 610 'Ramón y Cajal’ fellowship. 


\section{References}

Abad Viñas RA, Caudullo G, Oliveira S, de Rigo D (2016) Pinus pinaster in Europe: distribution, habitat, usage and threats. In: European Atlas of Forest Tree Species, p. e012d059+. Publ. Off. EU Luxembourg.

Alberto FJ, Aitken SN, Alía R, González-Martínez SC, Hänninen H, Kremer A, . . . Whetten R (2013a) Potential for evolutionary responses to climate changeevidence from tree populations. Global Change Biology 19, 1645-1661.

Alberto FJ, Derory J, Boury C, Frigerio J-M, Zimmermann NE, Kremer A (2013b) Imprints of natural selection along environmental gradients in phenology-related genes of Quercus petraea. Genetics 195, 495-512.

Alía R, Chambel R, Notivol E, Climent J, González-Martínez SC (2014) Environmentdependent microevolution in a Mediterranean pine (Pinus pinaster Aiton). BMC Evolutionary Biology 14, 200.

Alía R, Gil L, Pardos J (1995) Performance of 43 Pinus pinaster Ait. provenances on 5 locations in central Spain. Silvae Genetica 44, 75-80.

Andersson B, Fedorkov A (2004) Longitudinal differences in Scots pine frost hardiness. Silvae Genetica.

Bachtrog D (2008) Similar rates of protein adaptation in Drosophila miranda and D. melanogaster, two species with different current effective population sizes. BMC Evolutionary Biology 8, 334.

Beck EH, Heim R, Hansen J (2004) Plant resistance to cold stress: Mechanisms and environmental signals triggering frost hardening and dehardening. Journal of Biosciences 29, 449-459.

Bierne N, Eyre-Walker A (2004) The genomic rate of adaptive amino acid substitution in Drosophila. Molecular Biology And Evolution 21, 1350-1360.

Biswas S, Akey JM (2006) Genomic insights into positive selection. Trends Genet. 22, 437-445.

Bucci G, González-M artínez SC, Le Provost G, Plomion C, RIBEIRO M, Sebastiani F, ... Vendramin GG (2007) Range-wide phylogeography and gene zones in Pinus pinaster Ait. revealed by chloroplast microsatellite markers. Molecular Ecology 16, 2137-2153.

Burban C, Petit RJ (2003) Phylogeography of maritime pine inferred with organelle markers having contrasted inheritance. Molecular Ecology 12, 1487-1495.

Bustamante CD, Fledel-Alon A, Williamson S, Nielsen R, Hubisz MT, Glanowski S, . . . Clark AG (2005) Natural selection on protein-coding genes in the human genome. Nature 437, 1153-1157.

Bustamante CD, Nielsen R, Hartl DL (2003) Maximum likelihood and Bayesian methods for estimating the distribution of selective effects among classes of mutations using DNA polymorphism data. Theoretical Population Biology 63, 91-103.

Bustamante CD, Nielsen R, Sawyer SA, Olsen KM, Purugganan MD, Hartl DL (2002) The cost of inbreeding in Arabidopsis. Nature 416, 531-534.

Castro J, Zamora R, Hódar JA, Gómez JM (2002) Use of shrubs as nurse plants: a new technique for reforestation in Mediterranean mountains. Restoration ecology 10, 297-305.

Chambel MR, Climent J, Alia R (2007) Divergence among species and populations of Mediterranean pines in biomass allocation of seedlings grown under two watering regimes. Annals of Forest Science 64, 87-97. 
Chancerel E, Lepoittevin C, Le Provost G, Lin YC, Jaramillo-Correa JP, Eckert AJ, . . . Plomion C (2011) Development and implementation of a highly-multiplexed SNP array for genetic mapping in maritime pine and comparative mapping with loblolly pine. BMC Genomics 12.

Cheddadi R, Vendramin GG, Litt T, François L, Kageyama M, Lorentz S, . . Jost A (2006) Imprints of glacial refugia in the modern genetic diversity of Pinus sylvestris. Global Ecology and Biogeography 15, 271-282.

Chen J, Glémin S, Lascoux M (2017) Genetic diversity and the efficacy of purifying selection across plant and animal species. Molecular Biology And Evolution 34, 1417-1428.

Chen Z, Cao Z, Yu Z (2014) Identification and characterization of differentially expressed genes during incompatible interaction between the foliar rust Melampsora larici-populina and poplar. Genet Mol Res 13, 2082-2093.

Corcuera L, Gil-Pelegrin E, Notivol E (2011) Intraspecific variation in Pinus pinaster PSII photochemical efficiency in response to winter stress and freezing temperatures. PLoS ONE 6, e28772.

Corcuera L, Gil-Pelegrín E, Notivol E (2012) Differences in hydraulic architecture between mesic and xeric Pinus pinaster populations at the seedling stage. Tree Physiology, 32, 1442-1457.

Dvornyk V, Sirviö A, Mikkonen M, Savolainen O (2002) Low nucleotide diversity at the pal1 locus in the widely distributed Pinus sylvestsris. Mol. Biol. Evol. 19, 179-199.

Eckert AJ, Bower AD, González-M artínez SC, W e grzyn JL, Coop G, Neale DB (2010) Back to nature: ecological genomics of loblolly pine (Pinus taeda, Pinaceae). Molecular Ecology 19, 3789-3805.

Eckert AJ, Bower AD, Jermstad KD, Wegrzyn JL, Knaus BJ, Syring JV, Neale DB (2013a) Multilocus analyses reveal little evidence for lineage-wide adaptive evolution within major clades of soft pines (Pinus subgenus Strobus). Molecular Ecology 22, 5635-5650.

Eckert AJ, Wegrzyn JL, Liechty JD, Lee JM, Cumbie WP, Davis JM, . . Quesada T (2013b) The evolutionary genetics of the genes underlying phenotypic associations for loblolly pine (Pinus taeda, Pinaceae). Genetics 195, 1353-1372.

Eilertson KE, Booth JG, Bustamante CD (2012) SnIPRE: Selection Inference Using a Poisson Random Effects Model. Plos Computational Biology 8.

Eveno E, Collada C, Guevara MA, Leger V, Soto A, Diaz L, . . Garnier-Gere PH (2008) "Contrasting Patterns of Selection at Pinus pinaster Ait. Drought Stress Candidate Genes as Revealed by Genetic Differentiation Analyses". Mol Biol Evol 25, 417-437.

Excoffier L, Foll M, Petit RJ (2009) Genetic Consequences of Range Expansions. Annual Review of Ecology, Evolution, and Systematics 40, 481-501.

Eyre-Walker A, Keightley PD (2007) The distribution of fitness effects of new mutations. Nature reviews. Genetics 8, 610.

Eyre-Walker A, Keightley PD (2009) Estimating the rate of adaptive molecular evolution in the presence of slightly deleterious mutations and population size change. Molecular Biology And Evolution 26, 2097-2108.

Fay JC, Wu C-I (2000) Hitchhiking Under Positive Darwinian Selection. Genetics 155, 1405-1413.

Galiano L, Martínez-Vilalta J, Lloret F (2010) Drought-induced multifactor decline of Scots pine in the Pyrenees and potential vegetation change by the expansion of co-occurring oak species. Ecosystems 13, 978-991. 
Galtier N (2016) Adaptive protein evolution in animals and the effective population size hypothesis. Plos Genetics 12, e1005774.

García-Gil MR, Mikkonen M, Savolainen O (2003) Nucleotide diversity at two phytochrome loci along a latitudinal cline in Pinus sylvestris. Mol. Ecol. 12, 1195-1206.

Gaspar MJ, Velasco T, Feito I, Alía R, Majada J (2013) Genetic variation of drought tolerance in Pinus pinaster at three hierarchical levels: a comparison of induced osmotic stress and field testing. PLoS ONE 8, e79094.

Gillespie JH (2001) Is the population size of a species relevant to its evolution? Evolution 55, 2161-2169.

Gonzalez-Martinez SC, Alia R, Gil L (2002) Population genetic structure in a Mediterranean pine (Pinus pinaster Ait.): a comparison of allozyme markers and quantitative traits. Heredity 89, 199-206.

Gossmann T, Keightley P, Eyre-Walker A (2012) The Effect of Variation in the Effective Population Size on the Rate of Adaptive Molecular Evolution in Eukaryotes. Genome Biology and Evolution 4, 658-667.

Gossmann TI, Song B-H, Windsor AJ, Mitchell-Olds T, Dixon CJ, Kapralov MV, . . . Eyre-Walker A (2010) Genome wide analyses reveal little evidence for adaptive evolution in many plant species. Mol Biol Evol 27, 1822-1832.

Goulas E, Schubert M, Kieselbach T, Kleczkowski LA, Gardestrom P, Schroder W, Hurry V (2006) The chloroplast lumen and stromal proteomes of Arabidopsis thaliana show differential sensitivity to short- and long-term exposure to low temperature. Plant Journal 47, 720-734.

Gravel S, Henn BM, Gutenkunst RN, Indap AR, Marth GT, Clark AG, . . . Altshuler DL (2011) Demographic history and rare allele sharing among human populations. Proceedings of the National Academy of Sciences 108, 1198311988.

Grivet D, Climent J, Zabal-Aguirre M, Neale DB, Vendramin GG, González-Martínez SC (2013) Adaptive evolution of Mediterranean pines. Molecular phylogenetics and evolution 68, 555-566.

Grivet D, Sebastiani F, Alía R, Bataillon T, Torre S, Zabal-Aguirre M, . . GonzálezMartínez SC (2011) Molecular Footprints of Local Adaptation in Two Mediterranean Conifers. Molecular Biology And Evolution 28, 101-116.

Guindon S, Gascuel O (2003) A simple, fast, and accurate algorithm to estimate large phylogenies by maximum likelihood. Systematic Biology 52, 696-704.

Gullberg U (1985) Allozyme variation in Scots pine (Pinus sylvestris L.) in Sweden. Silvae. Genet. 34, 193-201.

Hodgins KA, Yeaman S, Nurkowski KA, Rieseberg LH, Aitken SN (2016) Expression divergence is correlated with sequence evolution but not positive selection in conifers. Molecular Biology And Evolution 33, 1502-1516.

Holefors A, Opseth L, Rosnes AKR, Ripel L, Snipen L, Fossdal CG, Olsen JE (2009) Identification of PaCOL1 and PaCOL2, two CONSTANS-like genes showing decreased transcript levels preceding short day induced growth cessation in Norway spruce. Plant Physiology and Biochemistry 47, 105-115.

Holliday JA, Ritland K, Aitken SN (2010) Widespread, ecologically relevant genetic markers developed from association mapping of climate-related traits in Sitka spruce (Picea sitchensis). New Phytologist 188, 501-514.

Hurme P, Repo T, Savolainen O, Paakkonen T (1997) Climatic adaptation of bud set and frost hardiness in Scots pine (Pinus sylvestris). Canadian Journal of Forest Research-Revue Canadienne De Recherche Forestiere 27, 716-723. 
Jaramillo-Correa J-P, Rodríguez-Quilón I, Grivet D, Lepoittevin C, Sebastiani F, Heuertz M, . . Vendramin GG (2015) Molecular proxies for climate maladaptation in a long-lived tree (Pinus pinaster Aiton, Pinaceae). Genetics 199, 793-807.

Jiang Y, Yang B, Harris NS, Deyholos MK (2007) Comparative proteomic analysis of $\mathrm{NaCl}$ stress-responsive proteins in Arabidopsis roots. Journal Of Experimental Botany 58, 3591-3607.

Jones AM, Thomas V, Bennett MH, Mansfield J, Grant M (2006) Modifications to the Arabidopsis defense proteome occur prior to significant transcriptional change in response to inoculation with Pseudomonas syringae. Plant Physiology 142, 1603-1620.

Karhu A, Hurme P, Karjalainen M, Karvonen P, Kärkkäinen K, Neale D, Savolainen O (1996) Do molecular markers reflect patterns of differentiation in adaptive traits of conifers? TAG Theoretical and Applied Genetics 93, 215-221.

Keightley PD, Eyre-Walker A (2012) Estimating the rate of adaptive molecular evolution when the evolutionary divergence between species is small. Journal Of Molecular Evolution 74, 61-68.

Kousathanas A, Halligan DL, Keightley PD (2014) Faster-X adaptive protein evolution in house mice. Genetics 196, 1131-1143.

Krakau U-K, Liesebach M, Aronen T, Lelu-Walter M-A, Schneck V (2013) Scots pine (Pinus sylvestris L.). In: Forest tree breeding in Europe, pp. 267-323. Springer.

Kremer A, Roussel G (1986) Subdivision of shoot growth of maritime pine (Pinus pinaster Ait.). Geographic variation of morphogenetical and phenological components [phyllotaxis, polycyclism, plastochron lenght time, provenances] 43.

Kujala S, Savolainen O (2012) Sequence variation patterns along a latitudinal cline in Scots pine (Pinus sylvestris): signs of clinal adaptation? Tree Genetics \& Genomes 8, 1451-1467.

Lamy J-B, Bouffier L, Burlett R, Plomion C, Cochard H, Delzon S (2011) Uniform selection as a primary force reducing population genetic differentiation of cavitation resistance across a species range. PLOS ONE, 6, e23476.

Lamy JB, Delzon S, Bouche PS, Alia R, Vendramin GG, Cochard H, Plomion C (2014) Limited genetic variability and phenotypic plasticity detected for cavitation resistance in a Mediterranean pine. New Phytologist 201, 874-886.

Lan T, Wang X-R, Zeng Q-Y (2013) Structural and functional evolution of positively selected sites in pine glutathione S-transferase enzyme family. Journal of Biological Chemistry 288, 24441-24451.

Lanfear R, Kokko H, Eyre-Walker A (2014) Population size and the rate of evolution. Trends in Ecology \& Evolution 29, 33-41.

Ledger S, Strayer C, Ashton F, Kay SA, Putterill J (2001) Analysis of the function of two circadian-regulated CONSTANS- LIKE genes. The Plant Journal 26, 1522.

Li J, Li H, Jakobsson M, Li SEN, SjÖDin PER, Lascoux M (2012) Joint analysis of demography and selection in population genetics: where do we stand and where could we go? Molecular Ecology 21, 28-44.

Lind-Riehl JF, Sullivan AR, Gailing O (2014) Evidence for selection on a CONSTANS-like gene between two red oak species. Annals Of Botany 113, 967-975. 
Lorenz WW, Alba R, Yu Y-S, Bordeaux JM, Simões M, Dean JF (2011) Microarray analysis and scale-free gene networks identify candidate regulators in droughtstressed roots of loblolly pine (P. taeda L.). BMC Genomics 12, 264.

Lourenço JM, Glémin S, Galtier N (2013) The rate of molecular adaptation in a changing environment. Molecular Biology And Evolution 30, 1292-1301.

Löytynoja A, Goldman N (2005) An algorithm for progressive multiple alignment of sequences with insertions. Proceedings Of The National Academy Of Sciences Of The United States Of America 102, 10557-10562.

Ma X-F, Hall D, Onge KRS, Jansson S, Ingvarsson PK (2010) Genetic differentiation, clinal variation and phenotypic associations with growth cessation across the Populus tremula photoperiodic pathway. Genetics 186, 1033-1044.

Mattila TM, Aalto EA, Toivainen T, Niittyvuopio A, Piltonen S, Kuittinen H, Savolainen O (2016) Selection for population-specific adaptation shaped patterns of variation in the photoperiod pathway genes in Arabidopsis lyrata during post-glacial colonization. Molecular Ecology 25, 581-597.

McDonald JH, Kreitman M (1991) Adaptive protein evolution at the Adh locus in Drosophila. Nature 351, 652-654.

Messer PW, Petrov DA (2013) Frequent adaptation and the McDonald-Kreitman test. Proceedings of the National Academy of Sciences 110, 8615-8620.

Mikola J (1982) Bud-set phenology as an indicator of climatic adaptation of Scots pine in Finland. Silva Fennica 16, 178-184.

Naydenov K, Senneville S, Beaulieu J, Tremblay F, Bousquet J (2007) Glacial vicariance in Eurasia: mitochondrial DNA evidence from Scots pine for a complex heritage involving genetically distinct refugia at mid-northern latitudes and in Asia Minor. BMC Evolutionary Biology, 7, 233 doi:10.1186/1471-21487-233.

Naydenov KD, Alexandrov A, Matevski V, Vasilevski K, Naydenov MK, Gyuleva V, . .. Kamary S (2014) Range-wide genetic structure of maritime pine predates the last glacial maximum: evidence from nuclear DNA. Hereditas 151, 1-13.

Nei M, Li WH (1979) Mathematical model for studying genetic variation in terms of restriction endonucleases. Proceedings of the National Academy of Sciences 76, 5269-5273.

Nielsen R (2005) Molecular signatures of natural selection. Annual Review of Genetics 39, 197-218.

Notivol E, Garcia-Gil M, Alia R, Savolainen O (2007) Genetic variation of growth rhythm traits in the limits of a latitudinal cline in Scots pine. Canadian Journal of Forest Research 37, 540-551.

Oleksyn J, Tjoelker MG, Reich PB (1998) Adaptation to changing environment in Scots pine populations across a latitudinal gradient. Silva Fennica 32, 129-140.

Palmé A, Pyhäjärvi T, Wachowiak W, Savolainen O (2009) Selection on nuclear genes in a Pinus phylogeny. Molecular Biology And Evolution 26, 893-905.

Peischl S, Dupanloup I, Kirkpatrick M, Excoffier L (2013) On the accumulation of deleterious mutations during range expansions. Molecular Ecology 22, 59725982.

Perdiguero P, Barbero MC, Cervera MT, Soto Á, Collada C (2012) Novel conserved segments are associated with differential expression patterns for Pinaceae dehydrins. Planta 236, 1863-1874.

Petit RJ, Bahrman N, Baradat P (1995) Comparison of genetic differentiation in maritime pine (Pinus pinaster Ait.) estimated using isozyme, total protein and terpenic loci. Heredity 75, 382-389. 
Petit RJ, Duminil J, Fineschi S, Hampe A, Salvini D, Vendramin GG (2005) Comparative organization of chloroplast, mitochondrial and nuclear diversity in plant populations. Molecular Ecology 14, 689-701.

Phifer-Rixey M, Bonhomme F, Boursot P, Churchill GA, Piálek J, Tucker PK, Nachman MW (2012) Adaptive evolution and effective population size in wild house mice. Molecular Biology And Evolution 29, 2949-2955.

Pyhäjärvi T, García-Gil MR, Knürr T, Mikkonen M, Wachowiak W, Savolainen O (2007) Demographic history has influenced nucleotide diversity in European Pinus sylvestris populations. Genetics 177, 1713-1724.

Pyhäjärvi T, Salmela MJ, Savolainen O (2008) Colonization routes of Pinus sylvestris inferred from distribution of mitochondrial DNA variation. Tree Genetics \& Genomes 4, 247-254.

Ramírez-Valiente JA, Robledo-Arnuncio JJ (2014) Adaptive consequences of humanmediated introgression for indigenous tree species: the case of a relict Pinus pinaster population. Tree Physiology 34, 1376-1387.

Richard S, Morency M-J, Drevet C, Jouanin L, Séguin A (2000) Isolation and characterization of a dehydrin gene from white spruce induced upon wounding, drought and cold stresses. Plant Molecular Biology 43, 1-10.

Richardson DM (2000) Ecology and biogeography of Pinus Cambridge University Press.

Ruttink T, Arend M, Morreel K, Storme V, Rombauts S, Fromm J, . . Rohde A (2007) A molecular timetable for apical bud formation and dormancy induction in poplar. The Plant Cell Online 19, 2370-2390.

Ryyppö A, Iivonen S, Rikala R, Sutinen ML, Vapaavuori E (1998) Responses of Scots pine seedlings to low root zone temperature in spring. Physiologia Plantarum 102, 503-512.

Santos-del-Blanco L, Notivol E, Zas R, Chambel MR, Majada J, Climent J (2010) Variation of early reproductive allocation in multi-site genetic trials of maritime pine and Aleppo pine. Forest Systems, 19, 381-392.

Savolainen O, Kujala ST, Sokol C, Pyhajarvi T, Avia K, Knurr T, ... Hicks S (2011) Adaptive potential of northernmost tree populations to climate change, with emphasis on Scots pine (Pinus sylvestris L.). J Hered 102, 526-536.

Savolainen O, Pyhäjärvi T, Knürr T (2007) Gene Flow and Local Adaptation in Trees. Annual Review of Ecology, Evolution, and Systematics 38, 595-619.

Sawyer SA, Hartl DL (1992) Population genetics of polymorphism and divergence. Genetics 132, 1161-1176.

Schrider DR, Kern AD (2016) S/HIC: Robust identification of soft and hard sweeps using machine learning. Plos Genetics 12, e1005928.

Serra-Varela MJ, Grivet D, Vincenot L, Broennimann O, Gonzalo-Jiménez J, Zimmermann NE (2015) Does phylogeographical structure relate to climatic niche divergence? A test using maritime pine (Pinus pinaster Ait.). Global Ecology and Geography, 24, 1302-1313.

Slotte T, Foxe JP, Hazzouri KM, Wright SI (2010) Genome-wide evidence for efficient positive and purifying selection in Capsella grandiflora, a plant species with a large effective population size. Mol Biol Evol 27, 1813-1821.

Smith CM, Rodriguez-Buey M, Karlsson J, Campbell M M (2004) The response of the poplar transcriptome to wounding and subsequent infection by a viral pathogen. New Phytologist 164, 123-136.

Smith NG, Eyre-Walker A (2002) Adaptive protein evolution in Drosophila. Nature 415, 1022-1024. 
Städler T, Haubold B, Merino C, Stephan W, Pfaffelhuber P (2009) The Impact of Sampling Schemes on the Site Frequency Spectrum in Nonequilibrium Subdivided Populations. Genetics 182, 205-216.

Strasburg JL, Kane NC, Raduski AR, Bonin A, Michelmore R, Rieseberg LH (2011) Effective Population Size Is Positively Correlated with Levels of Adaptive Divergence among Annual Sunflowers. Molecular Biology And Evolution 28, 1569-1580.

Taberlet P, Fumagalli L, Wust-Saucy A, Cosson J (1998) Comparative phylogeography and postglacial colonization routes in Europe. Molecular Ecology 7, 453-464.

Tajima F (1989) Statistical methods for testing the neutral mutation hypothesis by DNA polymorphism. Genetics 123, 585-595.

Tavaré S (1986) Some Probabilistic and Statistical Problems in the Analysis of DNA Sequences. In: Lectures on Mathematics in the Life Sciences Volume 17 (ed. Miura RM), pp. 57-86. American Mathematical Society, Providence, RI, USA.

Tellier A, Fischer I, Merino C, Xia H, Camus-Kulandaivelu L, Städler T, Stephan W (2011) Fitness effects of derived deleterious mutations in four closely related wild tomato species with spatial structure. Heredity 107, 189.

Velasco-Conde T, Yakovlev I, Majada J, Aranda I, Johnsen Ã (2012) Dehydrins in maritime pine (Pinus pinaster) and their expression related to drought stress response. Tree Genetics \& Genomes 8, 957-973.

Vendramin GG, Anzidei M, Madaghiele A, Bucci G (1998) Distribution of genetic diversity in Pinus pinaster Ait. as revealed by chloroplast microsatellites. Theoretical and Applied Genetics 97, 456-463.

Wachowiak W, Balk P, Savolainen O (2009) Search for nucleotide diversity patterns of local adaptation in dehydrins and other cold-related candidate genes in Scots pine (Pinus sylvestris L.). Tree Genetics \& Genomes 5, 117-132.

Watkinson JI, Sioson AA, Vasquez-Robinet C, Shukla M, Kumar D, Ellis M, . . . Watson LT (2003) Photosynthetic acclimation is reflected in specific patterns of gene expression in drought-stressed loblolly pine. Plant Physiology 133, 17021716.

Watterson GA (1975) On the number of segregating sites in genetical models without recombination. Theoretical Population Biology 7, 256-276.

Wegrzyn JL, Lee JM, Tearse BR, Neale DB (2008) TreeGenes: a forest tree genome database. International journal of plant genomics 2008.

Wei H, Yordanov YS, Georgieva T, Li X, Busov V (2013) Nitrogen deprivation promotes Populus root growth through global transcriptome reprogramming and activation of hierarchical genetic networks. New Phytologist 200, 483-497.

Welch JJ (2006) Estimating the genomewide rate of adaptive protein evolution in Drosophila. Genetics 173, 821-837.

Wright SI, Andolfatto P (2008) The impact of natural selection on the genome: emerging patterns in Drosophila and Arabidopsis. Annual Review of Ecology, Evolution, and Systematics 39.

Zeng K, Fu Y-X, Shi S, Wu C-I (2006) Statistical tests for detecting positive selection by utilizing high-frequency variants. Genetics 174, 1431-1439.

\section{Data Accessibility}

DNA sequences are deposited in GenBank under accessions MF385275-MF385581 and MF385585-MF397901. 


\section{Author Contribution}

961

962

DG, OS and SCGM conceived the study. AJE, DBN and SCGM designed and produced the sequence data sets. DG and KA analyzed the data and drafted the manuscript. AV and SCGM contributed to analyze the data. All the authors contributed to editing and revising the manuscript. 


\begin{tabular}{lcc} 
& Scots pine & maritime pine \\
\cline { 2 - 3 } Number of loci & 372 & 372 \\
Total length (bp) & 165,048 & 166,641 \\
Segregating sites & 1543 & 983 \\
Average length (bp) & 444 & 448 \\
$\theta_{w \text {-syn }}$ (stdev) & $0.0069(0.0090)$ & $0.0042(0.0054)$ \\
$\pi_{\text {syn }}$ (stdev) & $0.0063(0.0098)$ & $0.0044(0.0069)$ \\
$\theta_{w \text {-nsyn }}$ (stdev) & $0.0015(0.0027)$ & $0.0008(0.0014)$ \\
$\pi_{\text {nsyn }}$ (stdev) & $0.0013(0.0025)$ & $0.0009(0.0018)$ \\
$K_{s}$ (stdev) & $0.0323(0.0253)$ & $0.0375(0.0313)$ \\
$K_{a}$ (stdev) & $0.0070(0.0081)$ & $0.0070(0.0080)$ \\
$K_{a} / K_{s}($ stdev) & $0.3988(1.0366)$ & $0.3335(0.8254)$
\end{tabular}

bp=base pair

stdev $=$ standard deviation

syn=synonymous

nsyn=nonsynonymous

$\theta_{w}$ : average Watterson's nucleotide diversity (Watterson 1975) per site

$\pi$ : average Tajima's nucleotide diversity (Tajima 1989) per site

$K_{s}$ : number of synonymous substitutions per synonymous site with Jukes-Cantor correction, using $P$. taeda as outgroup

$K_{a}$ : number of non-synonymous substitutions per non-synonymous site with Jukes-Cantor correction, using $P$. taeda as outgroup 
979

980

981

982

\begin{tabular}{llccc}
\hline Locus set & Statistic & Scots pine & & maritime pine \\
\cline { 1 - 2 } \cline { 5 - 5 } Target & Tajima’s $D$ & $-0.5230[-0.8559,-0.1901]$ & & $0.1195[-0.2020,0.4410]$ \\
Target & Zeng et al.’s $E$ & $-0.3596[-0.6483,-0.0709]$ & & $0.5309[0.1473,0.9145]$ \\
Target & Fay and Wu's $H_{n}$ & $-0.0844[-0.2788,0.1100]$ & & $-0.5269[-0.9309,-0.1229]$ \\
Reference & Tajima’s $D$ & $-0.4776[-0.5831,-0.3720]$ & & $0.0106[-0.1122,0.1335]$ \\
Reference & Zeng et al.'s $E$ & $-0.3376[-0.4517,-0.2235]$ & & $0.2898[0.1566,0.4230]$ \\
Reference & Fay and Wu’s $H_{n}$ & $0.0610[-0.0483,0.1703]$ & & $-0.3077[-0.4587,-0.1567]$ \\
\hline
\end{tabular}

Table 2. SFS-based statistics for 64 target and 308 reference loci in Scots pine and maritime pine, with their 95\% Confidence Interval in square brackets. 
983 Table 3. Neutrality tests and type of selection for target genes in Scots pine and maritime 984 pine. Symbols in parenthesis represent genes related to biotic stress (S) and

985 phenology/photosystem (P).

986

\begin{tabular}{|c|c|c|c|c|}
\hline \multirow[t]{2}{*}{ Locus } & \multicolumn{2}{|c|}{ Scots pine } & \multicolumn{2}{|c|}{ maritime pine } \\
\hline & SnIPRE* & MKPRF & SnIPRE* & MKPRF \\
\hline dhn1 (S) & negative & negative & & negative \\
\hline dhn2 (S) & positive & positive & & \\
\hline dhn5 (S) & positive & positive & & \\
\hline $\operatorname{coL} 1(\mathrm{P})$ & positive & positive & positive & \\
\hline 0_4042_01 (S) & & & positive & positive \\
\hline 2_9480_01 (S) & & & negative & \\
\hline 0_12156_02 (P) & & positive & & \\
\hline
\end{tabular}

987

$988 *$ Only genes in common between the Empirical Bayes and the Bayesian SnIPRE tests are 989 reported. Outputs for each method are presented in full in Table S5.

990 


\section{$991 \quad$ Figure Legends}

992

993

994

995

996

997

998

999

1000

1001

1002

1003

1004
Figure1. Species distribution and sampling for Scots pine (blue, black dots) and maritime pine (green, red dots).

Figure 2. Distribution of Fitness Effects of new mutations (DFE) (a), and relative rate of adaptive substitutions $\omega_{a}$ (b) for the CRSP dataset in Scots pine and maritime pine, and for the "extended CRSP" dataset (only maritime pine), using the method II of Eyre-Walker and Keightley (2009), as implemented in DoFE. $N_{e} s$ denotes the product of the effective population size $N_{e}$ and the strength of selection $s$, with $N_{e} s<1$ corresponding to slightly deleterious mutations and $N_{e} s>100$ corresponding to highly deleterious mutations. Bars in (a) represent standard errors (with different letters indicating significant differences), while bars in (b) represent 95\% Confidence Intervals. 
1005

1006

1007
Figure1.

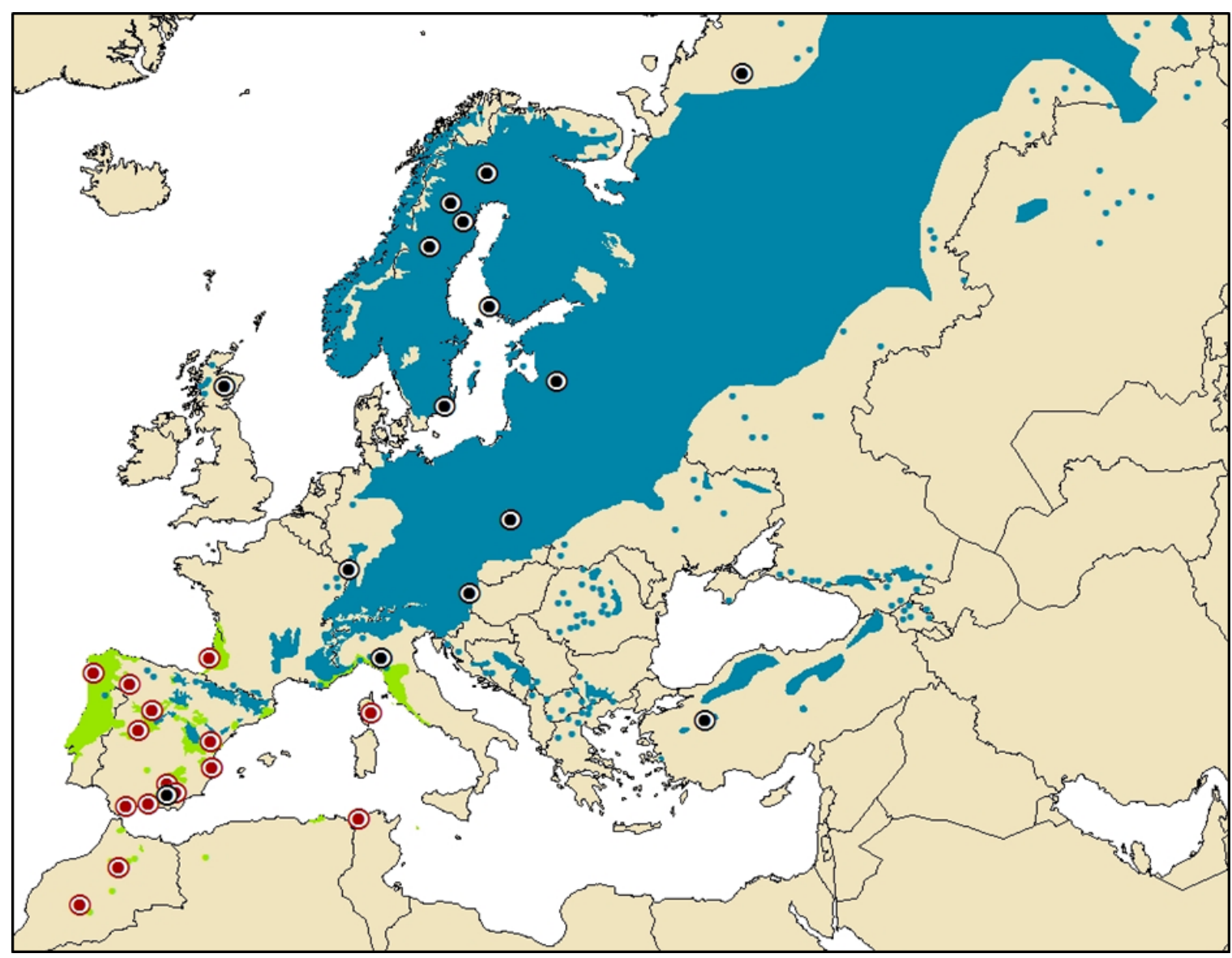


1013

1014
Figure 2.

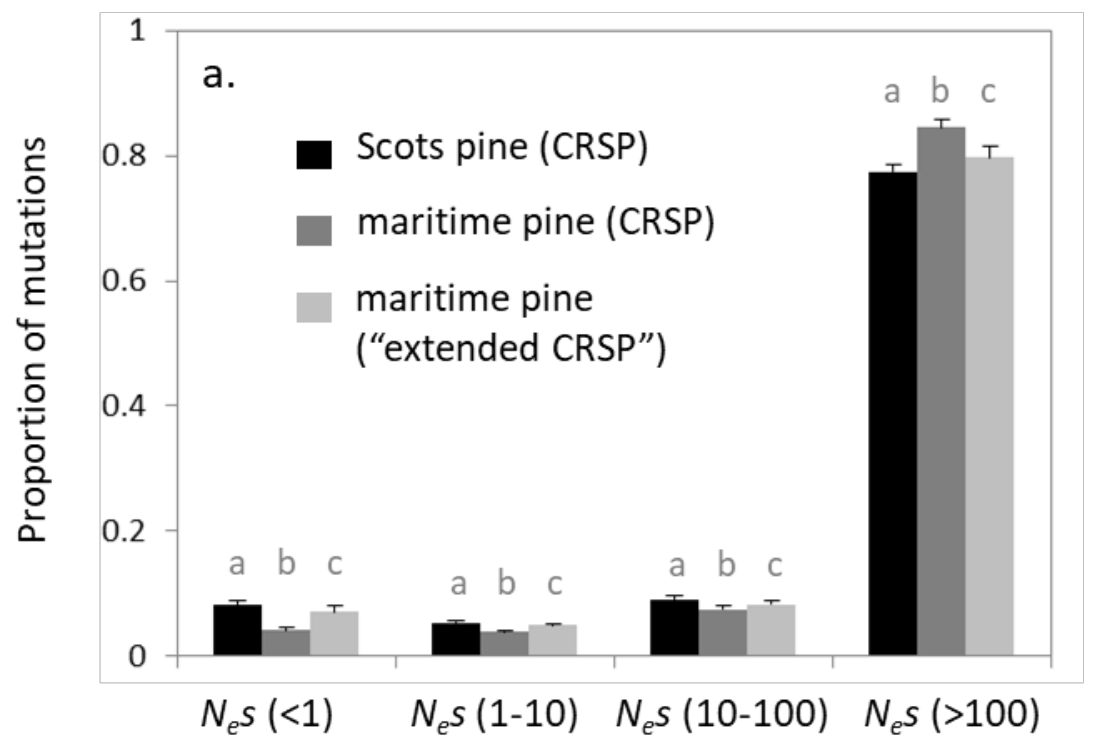

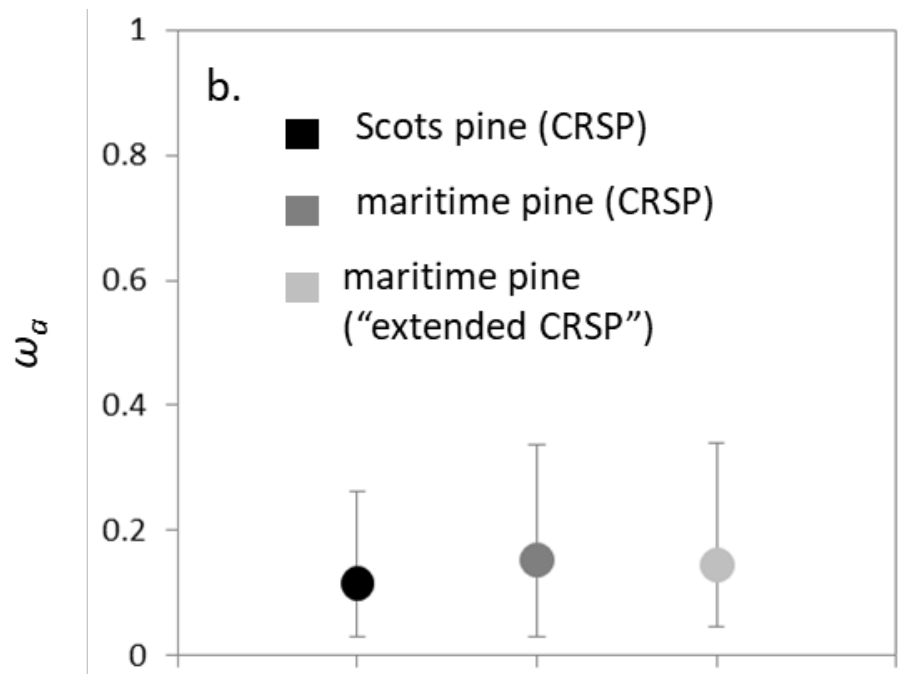


1 Figure S1. Molecular datasets used for the different analyses. Species abbreviations are as

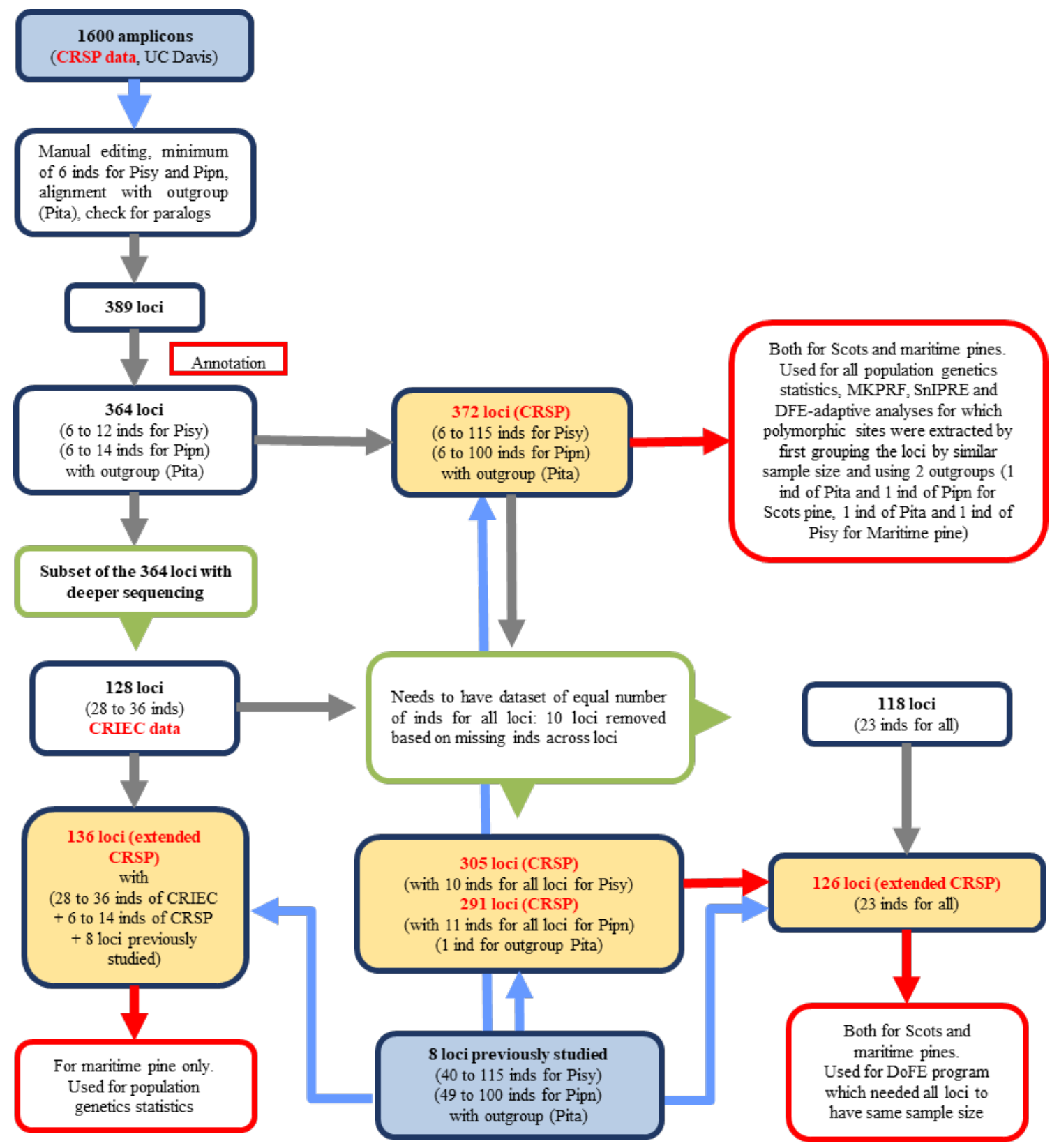


6 Figure S2. Selection events detected with the SnIPRE approach for the 64 target loci and

7 silent sites in Scots pine and maritime pine. The graphs represent the selection effect

8 (fixation rate of non-synonymous mutations) vs. constraint effect (deleterious mutations).

9

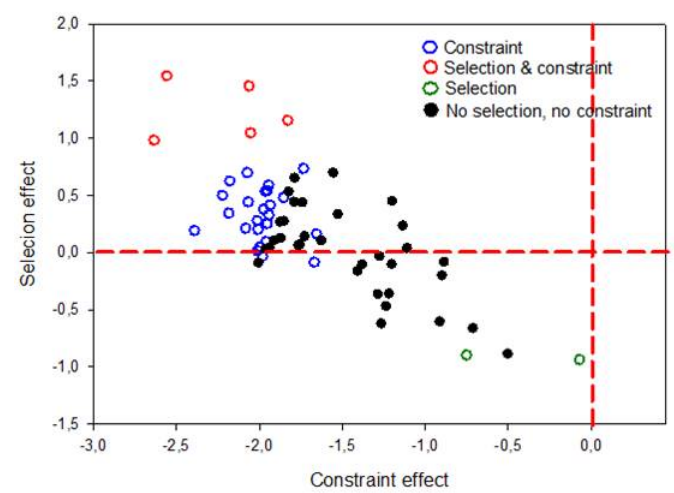

Empirical Bayes SnIPRE

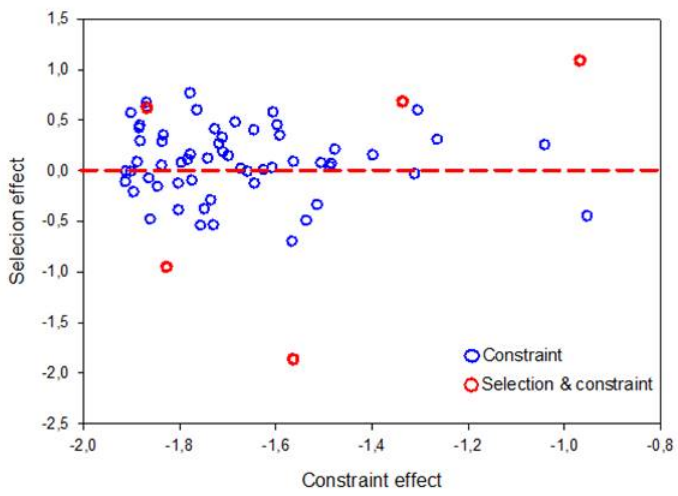

Empirical Bayes SnIPRE

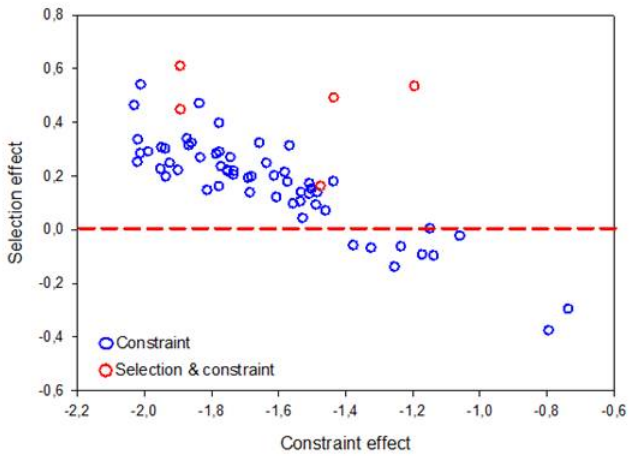

Bayesian SnIPRE
10

11

12

13
3
Scots pine

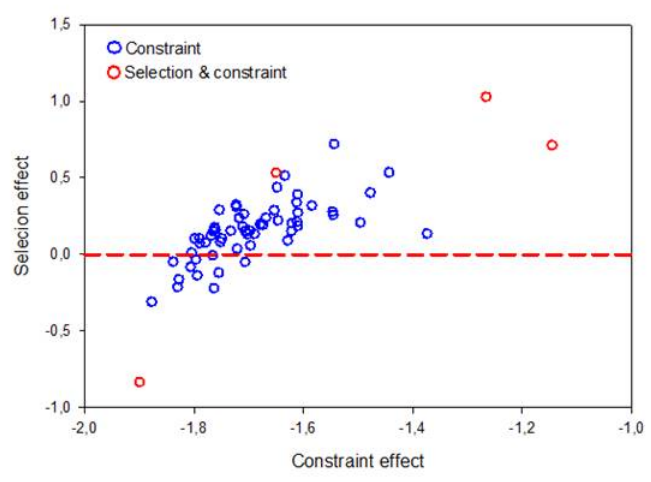

maritime pine 
Figure S3. Maximum likelihood three-species unrooted phylogenetic tree to estimate shared divergence between loblolly pine and Scots pine/maritime pine (see main text).

Example of branch length estimates using 168,534 bp of concatenated sequence per species (Pipn_1: one sequence for maritime pine, Pisy_1: one sequence for Scots pine and Pita_1: one sequence for loblolly pine).

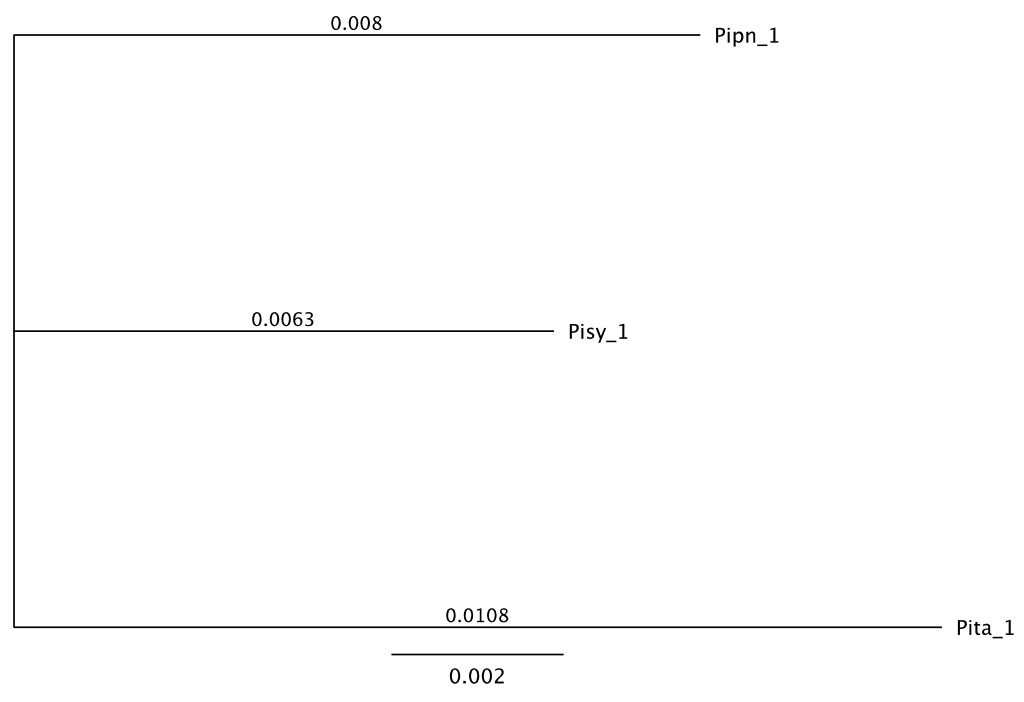


Table S1. Sampling for the two conifer species. Numbers under candidate genes' column correspond to the exact number of samples per population for each of the six previously studied candidate genes. For CRSP and "extended CRSP” datasets the numbers show the maximum sample size per population.

\begin{tabular}{|c|c|c|c|c|c|c|c|c|c|c|}
\hline Site & Country & Latitude & Longitude & \multicolumn{6}{|c|}{8 loci (6 genes) from candidate genes } & CRSP \\
\hline Kolari & Finland & 67.18 & 24.05 & 19 & 5 & 4 & 5 & 19 & 7 & 2 \\
\hline Usinsk & Russia & 66.08 & 57.5 & 7 & & & & 10 & 5 & \\
\hline Kaddekielas & Sweden & 66.07 & 19.1 & 8 & & & & 9 & 6 & \\
\hline Northern Sweden & Sweden & 65.13 & 20.23 & & & & & & & 1 \\
\hline Northern Sweden & Sweden & 64.15 & 16.07 & & & & & & & 1 \\
\hline Uusikaupunki & Finland & 60.87 & 21.33 & 10 & 5 & 4 & 5 & 10 & 5 & \\
\hline Eastern Scotland & UK & 57.05 & -3.27 & 10 & & & & 10 & 5 & 2 \\
\hline Kalsnava & Latvia & 56.75 & 25.88 & 9 & & & & 9 & 4 & \\
\hline Norra Gullabo & Sweden & 56.47 & 15.92 & 10 & 5 & 5 & 5 & 10 & 6 & \\
\hline Radom & Poland & 50.68 & 20.08 & 20 & 5 & 5 & 5 & 20 & 9 & 2 \\
\hline Haguenau & France & 48.85 & 7.87 & 10 & 5 & 4 & 5 & 9 & 6 & \\
\hline Oberloisdorf & Austria & 47.43 & 16.48 & & 5 & 5 & 5 & & & \\
\hline Parma & Italy & 44.62 & 10.15 & 10 & & & & 9 & 3 & 2 \\
\hline Kalabak & Turkey & 39.45 & 30.3 & & 5 & 5 & 5 & & & \\
\hline Sierra de Baza & Spain & 37.37 & -2.83 & & 5 & 4 & 5 & & & 2 \\
\hline Total (individuals) & & & & 113 & 40 & 36 & 40 & 115 & 56 & 12 \\
\hline Total (populations) & & & & 10 & 8 & 8 & 8 & 10 & 10 & 7 \\
\hline
\end{tabular}


maritime pine

\begin{tabular}{|c|c|c|c|c|c|c|c|c|c|c|c|}
\hline \multirow[t]{2}{*}{ Site } & \multirow[t]{2}{*}{ Country } & \multirow[t]{2}{*}{ Latitude } & \multirow[t]{2}{*}{ Longitude } & \multicolumn{6}{|c|}{8 loci (6 genes) from candidate genes } & \multirow[t]{2}{*}{ CRSP } & \multirow[t]{2}{*}{ CRIEC } \\
\hline & & & & coL1 1 & dhn1 & dhn2 & dhn5 & gia & $4 c l$ & & \\
\hline Landes & France & na & na & & & & & & & 3 & \\
\hline Pleucadec & France & 47.78 & -2.34 & & 5 & & & & & & \\
\hline Mimizan (Landes) & France & 44.13 & -1.3 & & 15 & 4 & 2 & & 1 & & 2 \\
\hline Galicia & Spain & na & na & & & & & & & 1 & \\
\hline Unknown origin* & France & na & na & & & & & & & 1 & \\
\hline Tabuyo del Monte & Spain & 42.3 & -6.22 & & & & & & & & 2 \\
\hline San Cipriano de Ribarteme & Spain & 42.12 & -8.36 & & 7 & & & & & & \\
\hline Pinia (Corsica) & France & 42.02 & 9.46 & 4 & 8 & 9 & 9 & 3 & 7 & & 2 \\
\hline Pineta (Corsica) & France & 41.96 & 9.04 & & 6 & & & & & & \\
\hline Coca & Spain & 41.23 & -4.5 & 13 & 17 & 15 & 13 & 10 & 16 & 2 & 4 \\
\hline Arenas de San Pedro & Spain & 40.19 & -5.12 & 12 & 19 & 15 & & 10 & 13 & 1 & 4 \\
\hline Olba & Spain & 40.17 & -0.62 & 4 & & 8 & 7 & 4 & 7 & 1 & 4 \\
\hline Quatretonda & Spain & 38.97 & -0.36 & 3 & & 8 & 6 & 4 & 5 & 1 & 4 \\
\hline Cazorla & Spain & 37.92 & -2.92 & 9 & & 7 & 7 & 9 & 9 & 1 & 4 \\
\hline Oria & Spain & 37.52 & -2.33 & 6 & 6 & 9 & 9 & 1 & 6 & 1 & 4 \\
\hline Tabarka & Tunisia & 36.94 & 8.7 & 5 & 10 & 8 & 8 & 4 & 9 & 1 & 2 \\
\hline Cómpeta & Spain & 36.85 & -3.88 & & & 1 & 4 & & 8 & & \\
\hline Estepona & Spain & 36.52 & -5.12 & & & & & & & & 2 \\
\hline Tamrabta & Morocco & 33.6 & -5.02 & 3 & 7 & 8 & 3 & 2 & 8 & 1 & 2 \\
\hline Sidi Meskour & Morocco & 31.47 & -6.83 & 1 & & & 1 & 2 & 3 & & \\
\hline Total (individuals) & & & & 60 & 100 & 92 & 77 & 49 & 92 & 14 & 36 \\
\hline Total (populations) & & & & 10 & 10 & 11 & 12 & 10 & 12 & 11 & 12 \\
\hline
\end{tabular}

* Parent of a QTL mapping progeny with only approximate known origin (France) 
Table S2. Description of the six previously studied candidate genes (8 loci).

\begin{tabular}{|c|c|c|c|}
\hline Locus & Length (bp) $^{\mathrm{a}}$ & Scots pine & maritime pine \\
\hline $4 c l(\text { exon } 1,2-3,5)^{b}$ & $516+360+251=1127$ & this study ${ }^{3}$ (accessions MF385276-MF385442) & Grivet et al. (2011) \\
\hline dhn-1 & 636 & Wachowiak et al. (2009) & Eveno et al. (2008) \\
\hline$d h n-2$ & 713 & Wachowiak et al. (2009) & Grivet et al. (2011) ${ }^{\mathrm{c}}$ \\
\hline$d h n-5$ & 559 & Wachowiak et al. (2009) & Grivet et al. (2011) \\
\hline coL1 & 3829 & $\begin{array}{l}\text { Pyhäjärvi et al. (2007); Kujala and Savolainen } \\
\text { (2012) }\end{array}$ & $\begin{array}{l}\text { this study }{ }^{1} \text { (accessions } \\
\text { MF385443-MF385502) }\end{array}$ \\
\hline gia & 1376 & $\begin{array}{l}\text { Pyhäjärvi et al. (2007); Kujala and Savolainen } \\
\text { (2012) }\end{array}$ & $\begin{array}{l}\text { this study }^{2} \text { (accessions } \\
\text { MF385510-MF385558) }\end{array}$ \\
\hline
\end{tabular}

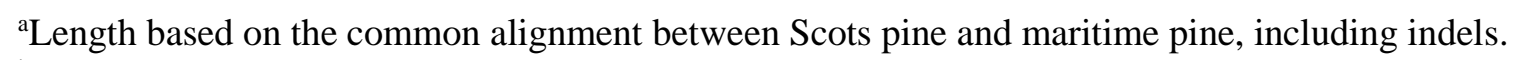

bExon_1, exon_2-3, exon_5 correspond to exon_c, exon_a, exon_b in Grivet et al. (2011).

'The candidate gene corresponds to dhn2-Ps.

${ }^{\mathrm{d}} \mathrm{dhn}-1$ corresponds to $d h n-9$ in Wachowiak et al. (2009).

${ }^{1}$ PCR reaction: for primer pairs Copr-promU2/ex1L1 and Copr-ex2U2/3utrL2 the $20 \mu$ mix of reaction contained $0.8 \mathrm{mM} \mathrm{dNTP}, 0.5 \mu \mathrm{M}$ of each primer, 1x Phusion HF Buffer (Phusion , Finnzymes), 25 ng DNA and 0.4 unit Taq polymerase (Phusion, Finnzymes); PCR conditions: 1 min at 98 ${ }^{\circ} \mathrm{C}$, 35 cycles of $10 \mathrm{sec}$ at $98{ }^{\circ} \mathrm{C}$, $30 \mathrm{sec}$ at $66^{\circ} \mathrm{C}$, $30 \mathrm{sec} 72{ }^{\circ} \mathrm{C}$, followed by $10 \mathrm{~min}$ at $72{ }^{\circ} \mathrm{C}$ (see primer's specification in Kujala and Savolainen 2012). For primer pairs Copr-109U/941L, Copr-718U/1919L and Copr1820U/1311L the $20 \mu \mathrm{lmix}$ of reaction contained $0.5 \mu \mathrm{M}$ of each primer, 1x Phusion Flash PCR Master Mix (Phusion Flash, Finnzymes) and 25 ng DNA. PCR conditions: 1 min at $98{ }^{\circ} \mathrm{C}$, 35 cycles of 10 sec at $98{ }^{\circ} \mathrm{C}$, 30 sec at $67^{\circ} \mathrm{C}$ (Copr-109U/941L) or $63{ }^{\circ} \mathrm{C}$ (Copr-718U/1919L and Copr1820U/1311L), 30 sec at $72{ }^{\circ} \mathrm{C}$, followed by 10 min at $72{ }^{\circ} \mathrm{C}($ see primer's specification in Kujala and Savolainen 2012).

${ }^{2}$ PCR reaction: the $20 \mu \mathrm{l}$ mix of reaction contained $0.8 \mathrm{mM}$ dNTP, $0.5 \mu \mathrm{M}$ of each primer, $1 \mathrm{x}$ Phusion HF Buffer (Phusion, Finnzymes), $25 \mathrm{ng}$ DNA and 0.8 unit Taq polymerase (Phusion, Finnzymes). PCR conditions: $1 \mathrm{~min}$ at $98^{\circ} \mathrm{C}, 35$ cycles of $10 \mathrm{sec}$ at $98{ }^{\circ} \mathrm{C}, 30 \mathrm{sec}$ at $65{ }^{\circ} \mathrm{C}(\mathrm{ex} 11-$ U1/3utr-L1) or $66^{\circ} \mathrm{C}$ (ex10-U1/ex11-L2), 1 min at $72{ }^{\circ} \mathrm{C}$, followed by $10 \mathrm{~min}$ at $72{ }^{\circ} \mathrm{C}$ (see primer's specification in Kujala and Savolainen 2012 ).

${ }^{3}$ PCR conditions are the same as in Kujala and Savolainen (2012), and primers are identical to those described in Grivet et al. (2011). 
Table S3. 64 target genes related to stress responses (S) and phenology/photosynthesis (P).

\begin{tabular}{|c|c|c|c|c|}
\hline Locus & Function & $\begin{array}{c}\text { E-value } \\
\text { Pinus EST }\end{array}$ & $\begin{array}{c}\text { E-value } \\
\text { A. thaliana }\end{array}$ & Length (bp) $^{\mathrm{a}}$ \\
\hline $4 c l(\text { exon } 1)^{b}$ & 4-coumarate_CoA ligase (S) & 0 & $7.00 \mathrm{E}-49$ & 515 \\
\hline $4 c l(\text { exon } 2-3)^{b}$ & 4-coumarate_CoA ligase (S) & 0 & $1.00 \mathrm{E}-24$ & 359 \\
\hline $4 c l(\text { exon } 5)^{b}$ & 4-coumarate_CoA ligase (S) & 0 & $1.00 \mathrm{E}-19$ & 249 \\
\hline$d h n-1^{c}$ & Dehydrin (S) & 0 & $5.00 \mathrm{E}-07$ & 601 \\
\hline$d h n-2^{d}$ & Dehydrin (S) & 0 & $5.00 \mathrm{E}-03$ & 573 \\
\hline dhn-5 & Dehydrin (S) & 0 & $6.00 \mathrm{E}-04$ & 386 \\
\hline 0_16976_02 & 3-ketoacyl-CoA synthase 6 (S) & na & $1.00 \mathrm{E}-41$ & 402 \\
\hline 0_18745_02 & Mitogen-activated protein kinase 4 (S) & $2.00 \mathrm{E}-089$ & 8.00E-17 & 685 \\
\hline 0_2070_01 & Heat stress transcription factor B-2b (S) & na & $7.00 \mathrm{E}-11$ & 411 \\
\hline 0_3790_01 & Phospholipase D alpha 1 (S) & $3.00 \mathrm{E}-120$ & $5.00 \mathrm{E}-35$ & 512 \\
\hline 0_4032_02 & ARM repeat superfamily protein (S) & na & $3.00 \mathrm{E}-28$ & 390 \\
\hline 0_4042_01 & Glutathione S-transferase TAU 8 (S) & $1.00 \mathrm{E}-169$ & $2.00 \mathrm{E}-21$ & 476 \\
\hline 0_4285_01 & Amino acid permease $3(\mathrm{~S})$ & 0 & $3.00 \mathrm{E}-27$ & 495 \\
\hline 0_6683_01 & Salt-inducible zinc finger $1(\mathrm{~S})$ & na & $6.00 \mathrm{E}-10$ & 459 \\
\hline 0_6878_01 & F-box leucine-rich repeat family protein MAX2 (S) & 7.00E-047 & $5.00 \mathrm{E}-62$ & 435 \\
\hline 0_768_02 & Putative protein kinase (S) & $1.00 \mathrm{E}-109$ & $1.00 \mathrm{E}-38$ & 481 \\
\hline 0_9082_01 & Putative beta-1,3-endoglucanase (S) & 0 & $2.00 \mathrm{E}-32$ & 421 \\
\hline 0_9524_02 & U-box domain-containing protein 41 (S) & na & $3.00 \mathrm{E}-25$ & 449 \\
\hline 0_990_01 & Putative calcium-binding protein CML25 (S) & na & $7.00 \mathrm{E}-30$ & 399 \\
\hline 2_1582_02 & DNAJ heat shock protein-like protein (S) & 0 & $9.00 \mathrm{E}-56$ & 457 \\
\hline 2_2931_01 & Ethylene-responsive transcription factor RAP2.4 (S) & 0 & 7.00E-33 & 454 \\
\hline 2_3319_01 & Autophagy-related protein 18D (S) & na & $2.00 \mathrm{E}-13$ & 325 \\
\hline 2_3726_02 & DNAJ heat shock protein-like protein (S) & na & $1.00 \mathrm{E}-28$ & 450 \\
\hline
\end{tabular}




\begin{tabular}{|c|c|}
\hline 2_6731_01 & F-box protein GID2 (S) \\
\hline CL1524Contig1_03 & Histidinol dehydrogenase (S) \\
\hline CL1536Contig1_03 & Mannose-1-phosphate guanylyltransferase (S) \\
\hline CL2332Contig1_01 & Calcium-dependent protein kinase 6 (S) \\
\hline CL263Contig2_03 & RNA-binding protein 47C' (S) \\
\hline CL3771Contig1_04 & Ubiquitin-conjugating enzyme E2 32 (S) \\
\hline$U M N \_2399 \_01$ & U-box domain-containing protein 13 (S) \\
\hline$U M N \_5272 \_01$ & 6-phosphogluconate dehydrogenase, decarboxylating 3 (S) \\
\hline UMN_CL132Contig1_03 & Malate dehydrogenase (S) \\
\hline 2_9480_01 & Malate dehydrogenase (S) \\
\hline 2_1014_01 & Heat stress transcription factor B-1 (S) \\
\hline 0_1123_01 & Heat shock protein 70B (S) \\
\hline 0_11591_01 & Protein auxin RESPONSE 4 (S) \\
\hline 0_11649_01 & Tubulin beta-8 chain (S) \\
\hline 0_11649_03 & Tubulin beta-2/beta-3 chain (S) \\
\hline 0_11684_01 & Coronatine-insensitive protein 1 (S) \\
\hline 0_12117_01 & Adenine nucleotide alpha hydrolase-like protein (S) \\
\hline 0_12896_01 & F-box protein SKIP2 (S) \\
\hline 0_143_01 & Peroxidase $15(\mathrm{~S})$ \\
\hline 0_17010_02 & Putative UDP-glucose 6-dehydrogenase 1 (S) \\
\hline 0_4588_01 & Aldehyde dehydrogenase 2B4 (S) \\
\hline CL1029Contig1_01 & Putative galactinol--sucrose galactosyltransferase 2 (S) \\
\hline CL305Contig1_05 & Dihydrolipoyl dehydrogenase 1 (S) \\
\hline CL3795Contig1_01 & Amino acid dehydrogenase family protein (S) \\
\hline 0_7921_01 & Glucose and ribitol dehydrogenase homolog 1 (S) \\
\hline 0_15991_01 & E3 ubiquitin-protein ligase COP1 (P) \\
\hline coL1 & Zinc finger protein Constans-like $3(\mathrm{P})$ \\
\hline gia & Gigantea protein $(\mathrm{P})$ \\
\hline 0_12156_01 & Inactive leucine-rich repeat receptor-like protein kinase \\
\hline
\end{tabular}

$\begin{array}{ccc}\text { na } & 4.00 \mathrm{E}-14 & 430 \\ 5.00 \mathrm{E}-053 & 3.00 \mathrm{E}-17 & 439 \\ 5.00 \mathrm{E}-105 & 6.00 \mathrm{E}-37 & 207 \\ 6.00 \mathrm{E}-057 & 3.00 \mathrm{E}-19 & 426 \\ 7.00 \mathrm{E}-047 & 6.00 \mathrm{E}-10 & 444 \\ 9.00 \mathrm{E}-091 & 3.00 \mathrm{E}-11 & 446 \\ 0 & 8.00 \mathrm{E}-27 & 437 \\ \text { na } & 3.00 \mathrm{E}-83 & 444 \\ 7.00 \mathrm{E}-026 & 3.00 \mathrm{E}-62 & 319 \\ \text { na } & 2.00 \mathrm{E}-63 & 420 \\ 1.00 \mathrm{E}-059 & 2.00 \mathrm{E}-06 & 431 \\ 0 & 1.00 \mathrm{E}-38 & 404 \\ 0 & 5.00 \mathrm{E}-33 & 419 \\ 6.00 \mathrm{E}-128 & 4.00 \mathrm{E}-84 & 572 \\ 0 & 2.00 \mathrm{E}-72 & 344 \\ 0 & 7.00 \mathrm{E}-37 & 491 \\ 0 & 2.00 \mathrm{E}-15 & 414 \\ 2.00 \mathrm{E}-136 & 5.00 \mathrm{E}-55 & 434 \\ \text { na } & 8.00 \mathrm{E}-22 & 434 \\ 0 & 1.00 \mathrm{E}-76 & 375 \\ \text { na } & 1.00 \mathrm{E}-14 & 218 \\ 3.00 \mathrm{E}-085 & 3.00 \mathrm{E}-13 & 427 \\ \text { na } & 6.00 \mathrm{E}-44 & 302 \\ \text { na } & 1.00 \mathrm{E}-21 & 545 \\ \text { na } & 2.00 \mathrm{E}-17 & 336 \\ \text { na } & 3.00 \mathrm{E}-17 & 317 \\ 0 & 8,00 \mathrm{E}-35 & 3797 \\ 0 & 1,00 \mathrm{E}-27 & 1287 \\ 0 & 4.00 \mathrm{E}-47 & 431 \\ & & \\ 0 & & \end{array}$




\section{CORYNE (P)}

\begin{tabular}{|c|c|c|c|}
\hline 0_12156_02 & $\begin{array}{l}\text { inactive leucine-rich repeat receptor-like protein kinase } \\
\text { CORYNE (P) }\end{array}$ & 0 & 7.00E-37 \\
\hline 0_16400_01 & Protein UNUSUAL FLORAL ORGANS (P) & 0 & $1.00 \mathrm{E}-49$ \\
\hline$U M N \_3408 \_01$ & histone-binding protein RBBP4 (P) & 0 & $2.00 \mathrm{E}-26$ \\
\hline 0_3723_01 & STRUBBELIG-receptor family 3 (P) & $2.00 \mathrm{E}-072$ & $3.00 \mathrm{E}-16$ \\
\hline 0_7454_01 & Probable serine/threonine-protein kinase (P) & na & $9.00 \mathrm{E}-17$ \\
\hline 0_8850_02 & Photosystem I P700 chlorophyll a apoprotein (P) & na & $1.00 \mathrm{E}-52$ \\
\hline 2_6995_01 & Phosphoenolpyruvate carboxylase 4 (P) & 0 & 3.00E-61 \\
\hline UMN_3561_02 & Photosystem II 47 kDa protein (P) & 0 & 3.00E-41 \\
\hline UMN_5101_03 & Cytochrome b6/f complex subunit V (P) & na & $2.00 \mathrm{E}-13$ \\
\hline UMN_6852_02 & Cytochrome f (P) & 0 & $1.00 \mathrm{E}-37$ \\
\hline$U M N \_6924 \_03$ & Photosystem II 47 kDa protein (P) & na & $2.00 \mathrm{E}-42$ \\
\hline CL1430Contig1_06 & $\begin{array}{l}\text { Pyrophosphate--fructose 6-phosphate 1-phosphotransferase } \\
\text { subunit alpha } 1 \text { (P) }\end{array}$ & $1.00 \mathrm{E}-056$ & 4.00E-19 \\
\hline
\end{tabular}

aLength based on the common alignment between Scots pine and maritime pine, including indels.

bexon-1, exon-2-3, exon-5 correspond to exon-c, exon- $a$, exon- $b$ respectively in Grivet et al. (2011).

' $d h n-1$ corresponds to $d h n-9$ in Wachowiak et al. (2009).

${ }^{d} d h n-2$ corresponds to dhn2-Ps in Grivet et al. (2011). 
Table S4. 28 compound reference loci obtained using linkage map information.

\begin{tabular}{|c|c|}
\hline Compound reference locus & Individual reference locus \\
\hline LG1_a & 0_18018_01, CL3054Contig1_01, UMN_1023_01 \\
\hline LG1_b & 0_15329_01,0_17206_01,0_17607_02 \\
\hline LG2_a & 2_9455_01, 0_8531_01, 0_9091_01, UMN_5867_01 \\
\hline LG2_b & 0_13929_02,0_16732_01,0_2217_01, 2_9087_01 \\
\hline LG3_a & 0_18261_01, 0_7001_01, UMN_3006_01, UMN_3444_01, UMN_927_01 \\
\hline LG3_b & 0_17082_01,0_5575_01,0_9448_01, 2_1528_01 \\
\hline LG3_c & 0_4756_01, 2_6618_01, 0_11270_01,0_12683_01, 0_846_01, CL814Contig1_06 \\
\hline LG4_a & 0_16068_01,0_9444_01, CL4511Contig1_02 \\
\hline LG4_b & 0_13383_01, 0_7171_01, 2_3591_03, CL1045Contig1_01, CL1238Contig1_01, UMN_1037_01 \\
\hline LG5_a & 0_10453_01, 0_6465_01, CL3037Contig1_06, CL3758Contig1_05, 0_18350_01 \\
\hline LG5_b & 0_10054_01, 2_3941_01, 2_5724_02, 2_9603_01, CL415Contig1_04 \\
\hline LG5_c & UMN_4904_01, 0_236_01, 2_2936_01, CL4342Contig1_01, UMN_801_01 \\
\hline LG6_a & 0_9383_01, 2_7725_01, 2_8852_01, CL1004Contig1_08, CL4432Contig1_04 \\
\hline LG6_b & 0_11980_01, 0_12929_02, 0_8359_01, 0_8844_01, 0_9329_02, 2_5064_01, CL544Contig1_03 \\
\hline LG7_a & 0_10667_02, 2_5996_01, CL1848Contig1_01, CL572Contig1_02 \\
\hline LG7_b & 0_1659_02, 0_18470_01, 0_2078_01, 2_5636_01, CL4470Contig1_01 \\
\hline LG7_c & 0_14976_01,0_4105_01, 0_4394_01, 2_6491_01, 2_9291_02 \\
\hline LG8_a & 0_10267_01, 0_14221_01, 2_3947_01, CL1455Contig1_07 \\
\hline LG8_b & 0_17127_01,0_6999_01, 2_2960_02, CL1698Contig1_01, CL3539Contig1_01 \\
\hline LG9_a & 0_17143_02, 2_10236_01, CL1694Contig1_04, UMN_6426_02 \\
\hline LG9_b & 2_5099_01, 2_7852_01, 2_9930_01 \\
\hline LG9_c & 0_13841_01, 0_16459_01, 2_684_01, 2_974_01 \\
\hline LG10_a & 0_12021_01, 0_12978_02, 2_4724_01, 2_6130_01 \\
\hline LG10_b & 0_13484_01, 0_16860_01, 2_6052_01, UMN_5833_01 \\
\hline LG11_a & 0_12190_02, 0_16009_01, 0_17247_02, 2_7918_01, CL2472Contig1_01 \\
\hline LG11_b & 0_16889_02, 0_2433_01, 0_5204_01, CL4023Contig1_01 \\
\hline
\end{tabular}


LG12_a

CL905Contig2_01, 0_16169_01, 0_2885_01, 0_3261_01

LG12_b

0_9922_01, 0_11090_01, 1_5675_01, 2_10212_01, UMN_2174_01 
Table S5. Loci found under selection with the Empirical Bayes SnIPRE and the Bayesian SnIPRE methods (for silent sites).

\begin{tabular}{|c|c|c|c|c|}
\hline \multirow[t]{2}{*}{ Locus } & \multicolumn{2}{|c|}{ Scots pine } & \multicolumn{2}{|c|}{ maritime pine } \\
\hline & $\begin{array}{c}\text { Empirical } \\
\text { Bayes } \\
\text { SnIPRE }\end{array}$ & $\begin{array}{c}\text { Bayesian } \\
\text { SnIPRE }\end{array}$ & $\begin{array}{c}\text { Empirical } \\
\text { Bayes } \\
\text { SnIPRE }\end{array}$ & $\begin{array}{c}\text { Bayesian } \\
\text { SnIPRE }\end{array}$ \\
\hline dhn1 (S) & negative & negative & & positive \\
\hline dhn2 (S) & positive & positive & & \\
\hline dhn5 (S) & positive & positive & & \\
\hline $\operatorname{coL} 1(P)$ & positive & positive & positive & positive \\
\hline 4cl_exon1 (S) & positive & & & \\
\hline 0_4042_01 (S) & & & positive & positive \\
\hline 2_9480_01 (S) & & & negative & negative \\
\hline 0_143_01 & & positive & & \\
\hline 0_3723_01 & negative & & & \\
\hline 0_4032_02 & & & positive & \\
\hline 0_4588_01 & & positive & & \\
\hline 0_9082_01 & positive & & & \\
\hline 0_11684_01 & & positive & & \\
\hline 0_11649_01 & & & negative & \\
\hline CL1430Contig1_06 & & positive & & \\
\hline Total positive & 5 & 7 & 3 & 3 \\
\hline Total negative & 3 & 2 & 2 & 1 \\
\hline Total & 8 & 9 & 5 & 4 \\
\hline
\end{tabular}


Table S6. Count of fixed differences between loblolly pine and Scots pine/maritime pine. "Originated in one species” refers to mutations that arose only in Scots pine or in maritime pine.

\begin{tabular}{lcccccccc}
\hline & \multicolumn{3}{c}{ Scots pine } & & \multicolumn{3}{c}{ maritime pine } \\
\cline { 2 - 3 } \cline { 7 - 8 } & All sites & 0-fold sites & 4-fold sites & & All sites & 0-fold sites & 4-fold sites \\
Fixed sites & 1868 & 402 & 333 & & 2199 & 446 & 412 \\
Shared sites & 1239 & 250 & 227 & & 1239 & 250 & 227 \\
Originated in one species & 629 & 152 & 106 & & 960 & 196 & 185 \\
\hline
\end{tabular}


Table S7. Bootstrapping procedure to compare nucleotide diversity estimates in loci transferred from loblolly pine to European pines (364 CRSP loci, $N=14$ ) with those randomly resampled from loblolly pine genome (about 6,000 loci available). Numbers in bold indicate significant departure from random set of loci.

\begin{tabular}{|c|c|c|c|c|c|c|c|}
\hline & S total & $\pi$ total & $\theta_{w}$ total & $\pi$ syn & $\theta_{w}$ syn & $\pi$ nsyn & $\theta_{w}$ nsyn \\
\hline Transferred loci set & 3.36 & 0.00213823 & 0.00253591 & 0.00480557 & 0.00560486 & 0.00093046 & 0.00112435 \\
\hline Low 95CI & 3.02 & 0.00188983 & 0.00225759 & 0.00412203 & 0.00490509 & 0.00074009 & 0.00091097 \\
\hline High 95CI & 3.70 & 0.00238664 & 0.00281423 & 0.00548911 & 0.00630463 & 0.00112082 & 0.00133772 \\
\hline \multicolumn{8}{|c|}{ 1,000 bootstraps (364 loci) } \\
\hline Low 95CI & 3.38 & 0.00307339 & 0.00342669 & 0.00466651 & 0.00524553 & 0.00103738 & 0.00122625 \\
\hline High 95CI & 4.48 & 0.00439749 & 0.00481324 & 0.00800163 & 0.00884918 & 0.00232990 & 0.00244981 \\
\hline
\end{tabular}

S total: number of segregating sites per locus; $\pi$ (total, syn, nsyn): Tajima's nucleotide diversity (Tajima 1989) for total sites, synonymous sites, and non-synonymous sites; $\theta_{w}$ (total, syn, nsyn): Watterson's nucleotide diversity (Watterson 1975) for total sites, synonymous sites, and nonsynonymous sites; 95Cl: 95\% Confidence Intervals. 
Table S8. Summary statistics for all sites, synonymous sites, non-synonymous sites and silent sites, for the two conifer species for all loci (target and reference genes) for the CRSP and for the "extended CRSP” datasets. Divergence estimates are given using loblolly pine as reference. Statistics were normalized for varying sample size across loci with the SDMTools package in R.

\begin{tabular}{lcccc}
\hline & \multicolumn{2}{c}{ Scots pine (CRSP) } & silent \\
\cline { 2 - 5 } & all & syn & & \\
$\theta_{w}$ (stdev) & $0.003302(0.003664)$ & $0.006871(0.008962)$ & $0.001470(0.002685)$ & $0.005588(0.006476)$ \\
$\pi$ (stdev) & $0.002926(0.003886)$ & $0.006346(0.009822)$ & $0.001254(0.002494)$ & $0.004978(0.006712)$ \\
Divergence (JC) (stdev) & $0.016598(0.010255)$ & $0.032276(0.025316)$ & $0.006973(0.008064)$ & $0.028613(0.018187)$ \\
\hline
\end{tabular}

\begin{tabular}{lcccc}
\hline & \multicolumn{4}{c}{ maritime pine (CRSP) } \\
all & syn & nsyn & silent \\
\cline { 2 - 5 }$\theta_{w}$ (stdev) & $0.002141(0.002162)$ & $0.004189(0.005440)$ & $0.000823(0.001393)$ & $0.003749(0.003783)$ \\
$\pi$ (stdev) & $0.002236(0.002507)$ & $0.004426(0.006942)$ & $0.000905(0.001803)$ & $0.003785(0.004145)$ \\
Divergence (JC) (stdev) & $0.019092(0.014916)$ & $0.037465(0.031322)$ & $0.007029(0.007974)$ & $0.033709(0.025498)$ \\
\hline
\end{tabular}

\begin{tabular}{lllll}
\hline & \multicolumn{4}{c}{ maritime pine (“extended CRSP”) } \\
all & \multicolumn{1}{c}{ syn } & \multicolumn{1}{c}{ nsyn } & \multicolumn{1}{c}{ silent } \\
\cline { 2 - 5 }$\theta_{\mathrm{w}}$ (stdev) & \multicolumn{1}{c}{$0.002588(0.001915)$} & $0.00463(0.005147)$ & $0.001016(0.00138)$ & $0.004193(0.003292)$ \\
$\pi$ (stdev) & $0.002912(0.00252)$ & $0.00543(0.006992)$ & $0.001083(0.001996)$ & $0.004768(0.00428)$ \\
Divergence (JC) (stdev) & $0.021141(0.015417)$ & $0.041243(0.036966)$ & $0.008142(0.009089)$ & $0.037145(0.030381)$ \\
\hline
\end{tabular}


Table S9. Nucleotide diversity for maritime pine with CRSP (364 loci + 8 previously studied loci $=372$ loci $)$ and "extended CRSP" $(128+8$ previously studied loci $=136$ loci $)$ datasets using bootstrap resampling with replacement for different number of loci (indicated in brackets).

\begin{tabular}{lcccc}
\hline & \multicolumn{2}{c}{ CRSP } & \multicolumn{2}{c}{ “extended CRSP” } \\
& $\pi$ silent & $\theta_{w}$ silent & $\pi$ silent & $\theta_{w}$ silent \\
\cline { 2 - 5 } & & & & \\
Full dataset & 0.003785 & 0.003749 & 0.004768 & 0.004193 \\
Lower 95\% CI & 0.003282 & 0.003174 & 0.004076 & 0.003580 \\
Higher 95\% CI & 0.004337 & 0.004358 & 0.005530 & 0.004770 \\
& & & & \\
Mean 1,000 bootstrats (10) & & & & \\
Lower 95\% CI & 0.001220 & 0.001436 & 0.002448 & 0.002319 \\
Higher 95\% CI & 0.007082 & 0.007389 & 0.007804 & 0.006756 \\
& & & & \\
Mean 1,000 bootstrats (50) & & & & \\
Lower 95\% CI & 0.002380 & 0.002398 & 0.003612 & 0.003248 \\
Higher 95\% CI & 0.005065 & 0.005451 & 0.005902 & 0.005192 \\
& & & & \\
Mean 1,000 bootstrats (100) & & & & \\
Lower 95\% CI & 0.002783 & 0.002826 & 0.003939 & 0.003579 \\
Higher 95\% CI & 0.004773 & 0.004946 & 0.005631 & 0.004904 \\
& & & & \\
\hline
\end{tabular}

Statistics were normalized for varying sample size across loci with the SDMTools package in R. 